\title{
Tratamiento de la parálisis general progresiva por el método de Wagner von Jauregg
}

\author{
P O R \\ PEDRO PARDO FIGUEROA \\ (CONCIUSION)
}

Creemos haber insistido suficientenente sobre los muy relativos y discutibles peligros y contraindicaciones de la piroteralpia, por lo que no insistiremos particularmente sobre esto. Es sabido que las lesiones ardiacas bien compen. sadas resisten bien el tratamiento malárico, siempre que se tengan bien precisadas la mayor o menor gravedad de las gortitis tan fiecuentes en los paralíticos generalcs.

En los sujetos en tratamiento (on la malaria cuyas fuerzas menguan rápiclamente o presentan icteria, se ha recurrido sistenáticamente entre nosolros a la monta administra. cion de sales le quinina a lo que frecuentemente se ha asociado el tratamiento arsenical. Lar experiericia de los casos tratados en el servicio del Dr. Honorio F. Dri,gado, muestra que la anemia simple no es suliciente a que se corten las fiebres.

Hemos dicho cuán infundados nos parecen los temores y precauciones que muchos autores creen necesalio adoptar en el afán de evitar "la propagación de la malarial" en la población vecina a los enfermos. Está demostrado por WaGNER vON JAURigg que estas formas de moculacion directa, artifi. cial, asexuda, del plasmodio es notoriamente sensible, no sólo a lats sates de quinina, sino aún a mumerosas sustancias medicamentosas, a cámbios en el régimen alimenticio y aún a las alteraciones climatéricas, no siendo aptas para ser ve. biculadas ti menos án propagadas por el huésped interme. 
diario habitual, el anophel maculipennis. El peligro de dfseminación a causa de los P. G. en tratamiento, es pues,"simplemente ilusorio.

No existe, que sepamos, un s6lo cass debidamente comprobado de propayación malárica de esta índole en la literatura médica. En el Asilo de Magdalena en lugar de aumentar el numero de paladicos espontáneos, ha disminuído de año en año; siendo notable el hecho de que en los dos fltimo años ha sido menester buscar sangre palúdicá en los hospitales de Lima casi todas ins veces que ha sido necesario ino. cular a los paralíticos generales.

Las numerosas investigaciones que día a día se sucedenacerca de este nuevo método de tratamiento de la parálisis general y la creciente experiencia que sobre el particular se obtiene, al mismo tiempo que demuestra la puerilictarl de muchas supuestas contra indicaciones y peligros, pone en evidencia su indiscutible superioridad sobre los otros méudos de tratamiento.

Al cerárcon los conceptos y nociones que anteceden el presentecapítulo, pod liamos darpor terminado este trabajo.

Nos detiene un momento en nuestro proposito el deseode añadir, pala concluir, algunos datos acerca de la importancia diagnóstica que polemos y debemos obtener de las peculiares inorlificaciones cito químicas que experimenta el líquido céfaloráquideo en la l'arálisis General Progresiva; los cuales, suscintamente, agruparemos en el próximo y altimo cápítulo.

\section{CAPITULO IV}

Valor diagnóstico de las modificaciones del líquide céfalo-raquídeo de la P. G. en relación a la posibilidad del tratamiento precozdelamisma

Todos los autores están de acuerdo en que cuanto más pronto se instituya el tratamiento malárico en la P. G. tanto más concluyentes serán los resultados que se obtengan.

Después de WAGNer, KIrSCHBAUM, MÜHLENS y muchos otros, Nolan Lewis, considerando su experiencia en el St. Elizabeth's Hospital de Washington, nos dice, tras de considerar los diversos casos estudiados microscópicamente, que 
aquellos que necesariamente representan los pocos ejemplos en los que el tratamiento result6 impotente, deben servir para insistir án más acerca de la urgencia de tratar estos casos tan tempranamente como sea posible, antes que las lesiones que la enfermedad origina en el cerebro y sus cubiertas, sean irreparables por la naturaleza, extension y antigüedad de aquellaıs.

Evitando la posibilibad de que se produzcau en el cerebro de los P. G. carnbios permanentes que dificulten la involución total de los síntonias físicos y mentales por la indicación precoz de la malaria, los beneficios derivados para el en. termo por la acción de está, serán más completos y eficaces.

Conviene recordar que las alteraciones cerebralss más importantes que se originan en los casos avanzados están caracterizadas, entre otros signos, por la atiofia, la esclerosis y la alteración de la arquicectura corticál; por desintegración de las células neuronales; abundante neoformación neuróglica, y por reacciones de la tánica adventicia vascular.

Creemos que la gravedad de estas alteraciones anatómi. cas que la entermedad abandonada a sí misma, determina en los elemcntos nobles del nuero-eje, deben alentarnos a evitar que aquellas se constituyan, instituyendo un tratamiento abortivo de P. G.

No importa que sea ya un hecho halagador, como lo bemos indicado en páginas procedentes, la posibilidad de ha. cer retrogradar las lesiones anatómicas bajo la acción del tratamiento máárico, pues siempre esta involución histologica y está retrogradación sintomática hacia la higidez será tanto más completa cuando más tempranamente se intervenga.

De allí que nos permitamos insistir, átin cuando sea muy brevemente, sobre la urgencia de establecer el diagnostico de los casos de P. G. que se nos encomienden, con toda la precocidlat pusible.

Por la importancia nosologica y social que este hecho reviste, séanos permitido hacer algunas consideraciones diagnósticas en general, para ocuparnos luego de las muy importantes informaciones que el estudio de las modificaciones que la entermedad imprime alliquido céfalo-raquídeo nos suministra.

Al hacer estas consideraciones diagnósticas nos hemos inspirado en los muy completos e importantes trabajos y recopilaciones realizadas por el Prof. Max NonNe, de Ham- 
burgo y los datos del Prof. Wilhelm Gennirict, de Kiel. Nos permitimos usar de sus datos estruísticos por la enorme importanciá demostrativa que ellos tienen y porser también los más recientes y completos que hemos logrado obtener.

El diaguóstico de lá síflis nerviosa presentá serias dificultades, que se van resolviendo fatvorableniente gracias a los perfeccionamientos recientemente alcanzados en el campo neuropsiquiatrico tanto del punto de vista clínico como serológico; técnicas combinadas que permiten un diagnóstico easi seguro no sólo en lo referente a sífilis congénitá y ad. quirida, simo principalinente en las manifestaciones para o metasifilíticas, en esá importante agrupación sintomática que constituye la tábes y la parálisis general.

Vamos a prescindir aquí de los importantes elementos que para el diágnóstico nos proporciona el exámen somático del enfermo, por habernos ya ocupado de ello al hacer el estudio de la sintomatología de la P. G.

Examinaremos brevemente algunos de los más indispensable elementos para hacer un buen diagnóstico diferencial entre las diversas formas de nearosifilis, las cuales podemos agruparlos así: $1^{\circ}$ basqueda del microorganismo; $2^{\circ}$ investigaciones serológicas en la sangre y en el líquidocéfalo raquídeo, incluyendo el exámen citoquímico de este Gltimo; $3^{\circ}$ investigáción clínica de los reflejos pupilares; y $4^{\circ}$ signos generales neurosiquiátricos. Comode estos dos filtimos grupos nos hemos ocuparlo ya, al hacer la descripeión de lá entermedád, sólo consideráremos los dos primeros.

$1^{\circ}$ Búsqueda del microorganismo causal.-Muy pocos son los autores que han logrado poner en evidencia el espi. roquete en el líquido raquideo. Ha sido hallado, pero tán sólo en limitado número de casos, habiéndose logrado cultivarlo (Nichols y Hougra). La mayoria de estos poquisimos haliargos son descubiertos de autopsia y casicarecen devalor por las modificaciones suatanciales que la muerte imprime a los elementos nerviosos, alterando la permeabilidad meníngea; no obstante que Sézary et PAILLARD dicen ha. berlo encontrado en un hemiplégico portador de una sífilis secundaria, doce horas antes de la maerte, caso tálvez único.

Broch y Schuiman, después de numerosas y pacientes busquedas en el 1 c. $z$. de 112 entermos afectos de sífilis, en 
todas sus variedades (incluyendo tahes ỵ parlisis general), no hall podirle hallarlo ui una sola vez.

De experimentes practicalos sobre conejos por inyecciones teriticulares de lípuido raquideo o sifilitico se ha compro. bado que el espriroquete (derinciendoforzadamente su presencia tan sólo por la positividaci de las inoculaciones) ha sido hallado en el 1 c. r. en cisos de sifilis primaria y sicundaria sin manifestaciones nerviosns, endos casos y sirmpuedespués de la octava semalla de la inoculación; en la sifilis secundaria del $2^{?}$ al $12^{\circ}$ nes, en siete casos, y muncat en la sífilis terciatiá.

Allemás, en casos de sífilis con síntomats netriosos osten. sibles, se le ha encontrado en meningitis sifilítica reciente, una vez; apephlija, y hemiphaja consecunia de siete meses, unat vez y de un año, otsa; en labes, dos casos; en parálisis

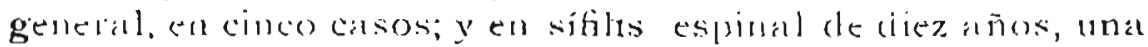
vez. En sililiti herelitionia, " pocal del nacimiento se hat hatllakb el espirouguete én el líquido céfalo-saquídeo, en dos carsos; ca dejtomeningitis tamiat, una voz, y en parálisis juvenil, that vez.

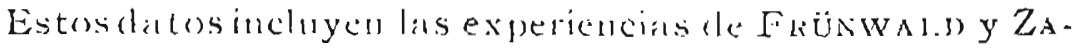
rozacckl praclicadals an 23 enternos probardos por este sistemar de inoculaciones a animales de cxperinentación, en los cuales los espriroquetess solo fuercu hallados cuatro veces en los 23 casos, uno en sililis secundaria reciente, otro en sifilis secundaliat avanzalda, man vezen meningitis reciente, y una tan sólo en P. G.

Los alutores mencionalos incluyen un crecido número de cásos de sifiliscerebral y de paraitisis general en lus cuales los resultados de las inoculaciones testiculates practicadas en conejosconel 1 c. r. centrifugadas extraidas a esos tntermos, fucron sicmpre negativos.

En la mayoria de estas investigaciones se ha seguido la ténica de Alzhrimer, quich trata el exudado extraido por el alcohol de $96^{\circ}$; así se precipitan las sustancies albuminosas y orgánicas y centrifugando después sé obtiene un coágulo que es tratado como una verdalerá picza biópsica y estudialat en cortes seriados.

Wurle y Kircher abrevian la rela tiva lentitud del procediniento anterior que afecta la morfología del espiroquete nñadiendo kaolin al líquido lo que permite la sedimentación y la tormación de una pasta albuminosa tratada por el óxido de amonio, con precipitado que se lava por decantacion. 
No entraremos en detalles de técnica, a pesar de los cuales queda siempre como conclusión final la general negatividad de estas in restigaciones.

No es prudente atribuir o explicar esta ausencia casi constante de treponemas en los líquidos examinados a la consecuencia de fenomenos líticos que determinárían la destrucción de siroquetes existentes pero citolizados. La ausencia de estas gupuestas lisinas de 1. c. r. fiente al treponemo ha sido demostrada, entre otros, principalmente por las inrestigaciones de Jeanselme, Schuimann y Martin.

Finalmente, las concepciones de Sézary sobre la génesis de los accidentes meníngeos que niega la localización primi. tiva del parásito en las meninges (fijándose primero en los centros nerviosos Hevado por la circulación general), terminan por restarle la muy relativa importancia que significa la presencia (muy dudosa) o ausencia del treponema en el 1. c. r. toda vez que esto no es sino un hecho secundario determinado principalmente por las relaciones de vecindad, de proximidad meningea a los focos cerebrales parenquimato. sos, infectádos.

Como una comprobación de lo que antecede, Frünwa LD y Za LOZIECKI incluyen un crecido numero de cásos de síflie cerebral y de parálisis general en los cuales los resultados de las inoculaciones testiculares practicadas en conejos con el 1 c. r. centrifugado, extraído a esos entermos, fueron siempre negativos.

Todo lo cual demuestra la extrema rarezá con que el ger. men se encuentra en el liquido célalo- raquídeo debido probablemente a la impermeabilidad aracnoidea; lo que explica la ineficacia de la salvarsanoterapia intrarraquídea. (Ya nos hemos ocupado de los hallazgosque del parásito se ha hecho en los diversos elementos hisulógicos del cerebro áe los P. G.)

$2^{\circ}$ Pruebas biológicas y serológicas practicadas en la sangre y en ei líquido céfílo raquíleo.

a) En la sangre.-Placticamente todas las formas resientes de sítilis nerviosal muestian un Borlet. Wassermann positivo en la sangre. Estos resultakos positivos que alcanzan de 96 a $100 \%$ en los casos recientes de sifilis ne viosa, se reduce al 70\% en sus tases ulteriores, para descender al 50\% en el periodo de latencia. Esstos resultados son notablemente modificados por el uso del alcohol y restiltan mug inciertos si el enfermo ha ingerido bebialas alcoholicas a an 45 ho. ras álutes de practicar la reacción. 
b) En el liquido céfalo-raquídeo.-El modo de conducirse de esta reacción es de la más alta importancia para el diagnosticu y tratamiento de la siflis nerviosa. Es casi uniforme en los casos de parálisis general, án cuando tan solo se usen en la reacción cantidades pequeñas de suero $(0.2 \mathrm{cc}$.) Este dato cunntitativo es de grande importancia y al efecto Hauptan y Hossi han tratado de demostrar que la paralisis general debía ser separada de las otras formas de nearosífilis tan sólo por este hecho, puesto que a excepción de la P. G., todas las otras formas requieren para dar resultados positivos con la $B$. W. mayores cantidades de liquido raquídeo, 0.8 a 1.2 (Thomson) y aún 2 cc. eliminando el factor anticomplementario en el diagnóstico diferencial entre la P. G. y la sífilis cerebral.

Esto desde luego, siempre que se tenga en cuenta la intesidad del proceso, puesto que los compromisos meníngeos cerebrales o medulares tienden a exhibir intensus reacciones positivas, mientras que las lesiones vasculares intracerebrales muestran más débiles reacciones tanto serológicas como citológicas; lo contratio de lo cual ocurre con los tipos parenquimatosos centrales, P. G. circunstancias que pueden explicarse por el confinamiento de las sustancias reaccionantes en el espacio subaracnoideo, o porque las lesiones no están en contacto directo, con el líquido espinal.

De otro lado, la síflis que no presenta compromiso del lado del sistema nervioso, de siempre resultados negativos en el líçuido céfalo taquuíleo, aún cuando se empleen cantida. des considerables le fluido. Es interesante anotar que, en reciprocidad, en todos los casos de sífilis nerviosa (parálisis general progresiva, principalmente), la Bordet-Wassermannes precozinate positiva y "existe ya una pleocitosis mucho antes de la aparición de los sintomas neurológicos y psiquiátricos."

Además, es interesante anotarel hecho frecuente de la ne. gatividad de la R. W. en la sangre y su positividad en 1. c. r., debido probablementeal empleo de cantidades crecidas del liquido raquíleo, que permite poner en evidencia "las me"ores cantiulades de anticuerpo o sustancias lipodotropicas" "reagin" de Nisissiar. Posiblemente estas sustancias pueden producirse en una proporción determinala en los tejidos del cerebro y médulá espinal en los casos de síflis del sistema nervioso central, pasando más al 1. c. r. que a la sángre, por razón de fáctolés patologicos (Kor,mir). 
$3^{0}$-Exámen citológico del líquido céalo-raquídeo-Modificaciunes bio-quinncas.-Su valor diagnóstico en neurosífilis.-Es este el otro elemento diangnstico, el que excede en importancia a los anteriormente nombrados, descle la casi impracticabifilad del hallazgo del teponema en el l. c. r.y dala también la frecuente negatividad de la $R$. W. en el suero sanguineo de sujetos portadores de man nenrosifilis latente o de una P. G. que se inicia y 'uya sintomatologia a un no se hat hecho ostensible.

Expondremos, brevenente, en esta úlima accion, algunosclatos que consideramos de importancia, comenzando por los que se relácionan eon el liefuido céfulo-saquideo "normal", pasa revisar después las más importantes alteraciones que este experinenta en has diversas variedades de sífilia norviosa y, col especial, en la P'. G.

Creemos conveniente anolas que cuando se habla de l. c. r. "normal", se retiete uno a un líguiclo no meningitico ni luético, pues el término "nomal" no puede precisalse debido a que las condiciones en que generalmente se estudial emanen de funciones tealizadas con fines terapéuticos y de investigacibn diagnósticn, o de punciones post-mortent.

Practicadala punción racfundea por mimera vez por Qun. QUE en 1890, su práctica se hat idlo extendiendor pregresivatmente.

Obtenido el líquido gencralmente por punción raquidea baja, entre la $3^{3}$ y $4^{a}$ lumbar, pues ma va bay que recurrir a la trépano-punción ventricular (practicada de preferencia en el lactante), tiene su origen, como es sabido, principalmente en los plexos coroides y de modo accesorion en el epitelio ependimario y en las valuas perivasculares, le donde por un movamiento lento se reparte, a través del algujero de Monro. delosventriculos laterales al ventrículo nedio, el cuarto ventriculo por el acheducto de Syrovius, a los lagos cerebelos-bulbares, a los espacios subaracnoideos de la base y médula, palra ser finalmente reabsorvido a nivel de los senos venosos por intermedio de las granulaciones de Paccioni y de los elementos peri-vasculares.

A pesar de las objeciones aducidas por Schmorl, entre otros, para demostrar que no existe commicación entre ell líquido de los ventrículos cerebrales y el de los espacios sub- 
a racnoideos del cerebro y mérlulá, esta comunicación se efec-

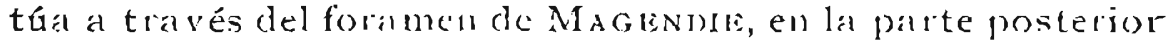
delcuarloventriculo, lel de I,USCHCA y otros que se abrein en los rentriculos laterales, como lo demuestral el hecho de que substancias coloreathas introducidas en los ventriculos pueden ser recogidas minutos désuéa por punción lumbar.

Representa ell. c. r. una esprecir de fillrado electivo de la parte dialuzable del suebo sanguíneo, más lat ablumina modi.

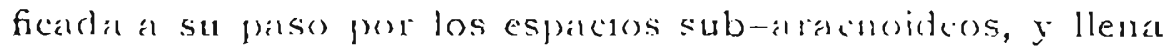
porsumasa el rol lísion de sostén de los elementos nerriosos, manteniendo ma igmakad de previon -como lo demostro

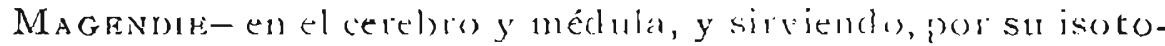
nicidad, de medio de conscrvación de los bementos netriosos.

Además, de acuerto con ha teoría de Mr. el l. ce r. su-

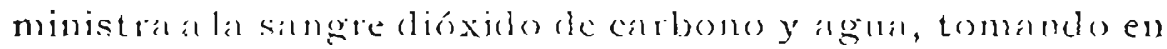

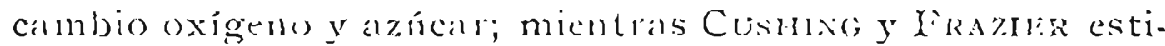
man que el líquido e. r. sería el medio de dislribución, a los tejudosdel sistema nerviose central, del principios actiro de la

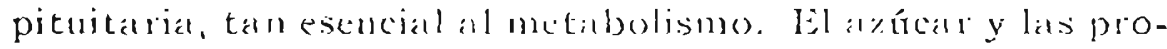
teínas que el liquido contiene servisian, además, fala mantener la energía de los elementos rea viosess y para reparal su desgaste.

Es un liquido claro, isotónico, por lo rute en estaclo normal no puede hemolizar los gholualos rojos, y en esta se basa

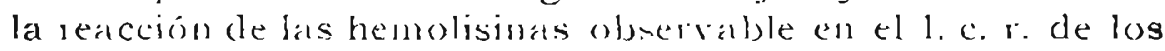
P. G.; teniendo una densidad alrededor de 1,008, y en poseción decubito lateral ke viete con uma pesión que varía entre 130 y $150 \mathrm{~mm}$. de agua (Qunck. I Hvisus), cifid que en estado patolígico sube a 200 y $300 \mathrm{~mm}$., pulliendo liegar esta presión a $800 \mathrm{~nm}$. de agran; sufie por lat respláacion os. cilaciones de $20 \mathrm{~mm}$ y pore el pulso, de $6 \mathrm{~mm}$.

Su compusicion (puisica, por litro, es de 0.15 a $0.30 \mathrm{gr}$. de albuminas; de 0.6 a 1.0 gri de glucosa; 0.15 a 0.40 de trea; 7 gr. de cloruros, y 8 gr. de cenizas, estando la masa total constiluida por agua.

No posee la propiedad complementiria del suero sangui. neo y soblo presenta por lo general, mo o dos clementos celu.

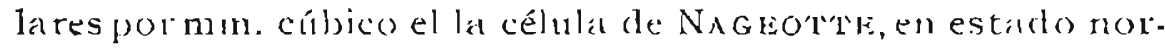
mal; alun cuando Genvier considera nomal de 3 a 6 linfocitos por num. c., de 6 a 9 como valor límite y más cle 9 co. mo pátológico.

De alli que las alteraciones que este líquilo experimenta en estado patológico, se refieren a "trastornos de la funcion 
secretora". que pueden determinar tanto el paso de sustancias anormales, como un aumento de la cantidad del mismo, que normalmente es de 120 a $150 \mathrm{cc}$., y a "trastornos de circulacion" por bloqueo de los organos de absorción, por variaciones de presion y por modificaciones citológicas de orígen meníngeo.

De paso diremos que la filtación electiva a nivel de los orga nos secretores por la relativa permeabilidad existente de fuerá adentro, explica la posibilidad de la invasion de este líquido porsustancias o elementos extraños (meningitis diversas), la que siendo mucho menor en sentido inverso no permite el paso n la circulación general o a la intimidad misma de loselementos nerviosos, de sustancias de composicion quimica compleja, como ocurre con los compuestos arsenicales. De allí la infructuosidad de las tentativas de terapia intraraquídea, en especial las de Swiffx. Ertuscon suerosalvarsanizado, no obstante que muchos autores creen que las mencionadas sustancias alumentan la perneabilidad neníngea.

Para concluír este parrafo, añadiremos que, sin pretender entráren detalles de ténica de la punción lumbar y sien. do ella indispensable para practicar estas investigaciones, conviene recordar que su práctica no está exenta de peligros, y que siendo una de las funciones del líquido céfalo-raquídeo mantener la igualdad de iresión intracerebral, su extraccion se practicata lentamente para evitar la brusca alteración de este equilibrio y sus desagradables consecuencias cefáleas, náuseas, vómitos y vértigos; hábiéudose señalado algunos casos de muterte srbita ocurrila en enfermos afectos de tumor cerebral a raíz de una panción lumbar.

Ocupermonos ahorade las "alteraciones patologicas" que ell.c. r. experimenta en las diveras formas de sífilis nerviosa.

Recordaremos que para Firichiman, el alumento de la "presión intrarraquiclea" $e$ s un signo premonitorio de importancia que inclica la invasion de las meninges por el agente infeccioso sifilitico, siendo este síntoma casi siempre anterior a la aparición de la linfocitoris. Según observaciones de Decovbaix, comprobadas por Rrim, de Munich, y por muchos otros, esta presión se halla aumentada en la palálisis gene. ral, en lá tabes y en la sifilis cerebral y medular. Este aumen. to puede observarse también en otras enfermedades crónicas 
cerebrales y medulares de origen n6 sifilitico: tumor, absceso, encefalitis, hidrocefalía, etc. por esta razón, considerado aisladamente, este dato carece de valor diagnóstico. En las enfermedades agudas -encefalitis, meningomielitis lueticaae observa también una presión de $150 \mathrm{~mm}$. y alan más, pero en estos casos este a umento va acompañado de una serie de trastornos subjetivos y objetivos, que no ocurre en las enfermedadescronicas ( $P$. G., tabes), en las que el sistema nervioso se ha adaptado a este aumento de presion lenta y progresiva, sin que se presente ninguno de tales trastornos.

En lo referente al "análisis químico", Donatra ha ellcontrado grandes alteraciones en la cantidad de ácido fostorico del líquido céfalo racuídeo en casos de parálisis general, como producto de desintegración de las lecitinas. P'ero estos datos son de inuy relativo valor diagubstico.

Es a Widal, a Ravaud, a Sicakd, y a Nageotre a quienes se debea los primeros tínbajos sobre cito-diagnóstico, en 1901. Estos autores por un largo procedimiento de centrifugación pusieron en evidencia la fuerte linfocitosisque se observa en paraláticos y tabélicos, resultados que mas tarde fueron ampliamente corroborados por investigadores alemanes. Schón born rátificó esto en 1906 al átirnar la precocidad de esta linfocitosis en la neurosífilis, indicando, que ello significaba uno de los datos má:s seguros e importantes para el diáguóstico de lá I’. G.

La verdad de esto.s hechos está hoy ampliamente demostrada y a las observaciones de autores anteriormente mencionados, anadiremos las de Eub, de la Clinica de Krappelin,

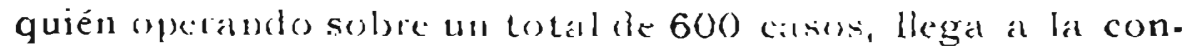
clusion del enorme valor diagnóstico que tiene una linfocito. sis por ligera que sta si va aconnuanada de rigidéz pupilar o algún otro signo de sítilis preexistente.

Debemos recordar alemás, de acuerdo con las observa.

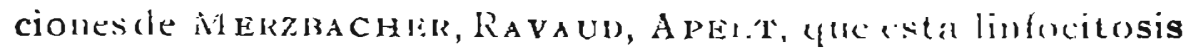
céfalo raquílea, prede sulssistir despuss de curadar la siffis (40\% \% los casess). Lat imprortancia de esta "linfocitosis residual", explicadia según Pierte Marreconso explesión de una sitilis thenugea, es digha de tenerse en contideracion para prever el futuro prosible de estos sifilitions "culador", a quie-

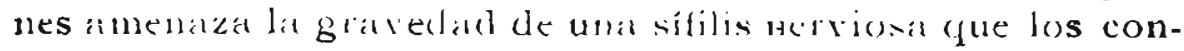
duzca a má palálisis general porotesiva.

Demostrado está por numerosos invertigadores que uno de los rasgos más característicos en un líquido céfalo raquí- 
deo patológico (newrosifilis) "es el aumento de linfocitos", que debe inducir a sospecha cuando pasa te 6 p. mm. c., y que se hace notoriamente signiticativo cannolo alcanza de 7 a 10 elenentos por mm. C. pulicudo seguirse paral su inves-

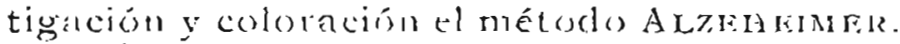

Roconbremos, de fasos, que el liquirlo céfialo.raquídeo "normal" esclato, con un peson especílico de 10,006, reacción ligeramente alealina y tan solo con 1 a 6 linfocitos por $\mathrm{mm}$.

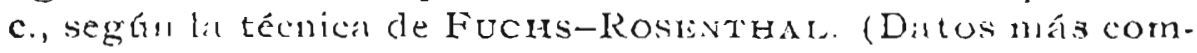
pletos offecermos en heve).

En la sifilis cerebro-espinal, en la tabes y en la parálisis general, hay casi siempre una hipertinfocitesis maniliesta, salvo en los casos muy antiguns y en los periudos de latencia. Este aumento puede alcanzar cifias elevalisimas-hasta 200 y án más por mus. c. - essuecialmente en meningomieli. tis agucla y en cassos fulminantes de parálisis general.

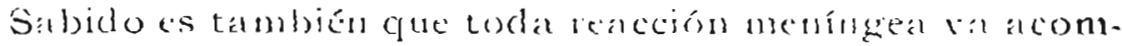
pánada de un aumento de linfocitos, ertando bos procesos aguclos caracterizatos per la presencial de poliancleosis, y

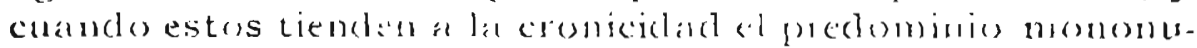
clear se hace evilente. Lal pieocicosis que se whstrat en todo

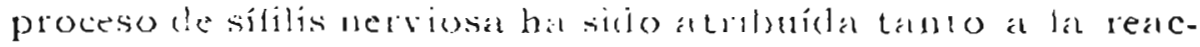
cion meningea-"sifiosis meningea" de Pierte Makri-de. termanala por la infeción, como al procesos consecutivo de periarteritis (Szécsi).

En cuanto al on ígen de estos linfocitos. son muchos los antores que se inclinan del lado del onigen hemalógeno ínico (NrssL) creyendo otros que esta linfocitosis se genera en las células tijas de los tejiclos (elementos perivasculares de la aracuoides, ete.), cotno opira Fischel (teoria histiogena). Sin embargo, la gran semejanza entre los linfocilos del líquido céfaloraquíleo y los leucocitos de la sangrepatecedemos. trar el origen sanguíneo de los primeros, siencio cuestión secundariadeterminarla manera cómo estoselementos han lo. grado penetrar al líquide mismo. En cuanto a los tibroblastos, estos sí procederían, según EskUcian, de elenentos histógenos. Es muy discuticlo el origgen de los macrifagos y cé. lulas plasmáticus; por lo cual no insistiremos, indicando soamente que SzésCi que ve en la pleocitosis la expresion de una "periarteritis cerebro espunal", considera tanto a las ce. ulas plasmáticas como a la mayoria de los elementos celala. res del líquido como provenientes de los tejidos meníngeos in. filtrados. Nada se sabe tampoco con precision si estos ele. 
mentos celulares, linfocitos y celulas plasmáticas, llegan al líquido raquídeo por migración autónoma a través del epéndimo, osi se encuentran allí en estado de inutilidad funcional o, ffualmente, si tienen la misión cle carryarse de los productos de desintegración que el proceso paralitico o tabético detern.ina en la sustancial nerviosal.

Es sabicio también, y así lo ha comprobado KaFkA y otros antores, que el grarlo de linfocitosis 130 guarda siempte relacion con la nguteza o condiciad bel cuadro clínico.

Por estudios especiales practicados, pátrece ser que las cifras más bajas de linfocitosis corresponden a la sifilis cerebral; una linfocitasis nás racentuadal es propiá de la tabes, mientras que las más altas son propias de la $P$. G. hecho que se ha constatado, entre nosotros, en los casos tral tados. Sin embargo, esto que es exacto en la mályoría de los cásos, dista de ser la regla. En efecto, la linfocitosis raquidea parece estar más ta relación con lá actividad del proceso causal de initación meningea (spiroyuete), que con su naturaleza. Asi se explicá que un proceso tabélico estacionario o uná P. G. en período de remisión, ofiezcan una linfocitosis reducida, mientras ocurre lo contrario con una sifilis cerebro-espinal aguda. El predominio de los polinucleares es un indice cierto de lá excesiva activialal del proceso. Creenos haber anotadoyacomodato impor ante el hechode que la pleocitosis en la tabes y en especial en la P. G., "preceden" a la apariciónde los sintonas y alteraciones neurológicas. lo cual es de grán interés cuando se intenta estahlecer un diágnóstico precoz.

Este modode revelirse tl periodo pre-parético sobre el que tanto hán insistido Sicakd, Kavaud, Cornaz, Firdes y otros, puedediaguosticarse hasta los años antes del estallido de lá enfermedad. Secomprende lar enorme importanciáque estos hechos revisten, cuando se les considera del punto de vistá médico social en lo relalivo al matrimonio de personas portadoras de una infeccionsifilitica batente y de remoto origen.

Sabemos que son relativamente tardías estas manifestaciones preparélicas; jero carbe preguntarse, ¿al cabo de cuanto tiempo de la infección de origen se inician los primeros síntomas de uná parálisis general? En esto, como en tantas otras cuestiones nosológicas, resulta imposible sentar reglas fijas. Así, Rava Úl citá un caso en que la aparición de los síntomas pátéticos estaban tan sólo separados de la infección de origen por un período de dos meses. Pero estos casos son raros. 
Lo frecuente es constatar cambios precoces en la composición del líquido céfalo-raquideo, en ausencia de toda maniféstación clínica, y que ésta se haga ostensible tan sólo meses o años más táde.

Al respecto, FiLdes citá un caso que a los cinco meses de la infección y sin tener ningun sintona clinico revelador de la neurosífilis que babía de desarrollar más tarde, presentaba ya, tan prematuramente, una intensa linfocitosis en el líquido céfilo raquídeo, tan intensá que alcanzaba a 1000 elementos (!) por mm. cúbico, a más de lá presencia de algunos espiroquetes. Este autor presenta estadisticas que se refieren a 624 casos de sifilis tomados al azar, 18\% de los cuales presentaban 100 más células por mm. cúbico y $12 \%$ tenían de 5 a 9 linfocitos por mm. c. En un $80 \%$ a de estos entermos que presentaban alteraciones diversas en la composicion del líquido céfalo raquiden, no había, sin embargo, signo clínico nlguno reveladoi de la seurosíflis existente, ni síntomas de alteración nerviosa, aun cuando 29 de ellos tenían más de 100 céluirs por mm. c., 9 por encima de 300 , y 3 tuvieron una pleocitosis de 1000 célulus por min. c.

Tan sólo un $20 \%$ de está considerable cantidad de enfer. mos presentaron sintomas clínicos antes de que las alteraraciones del líquido célalo raquidico se hicieran ostensibles; pero estas manifistaciones clüicas fueron tan iusignificantes que sólo con ellas no habría sido posible un diagnostico seguro sin las corroboraciones serolúgicas que se hicieron después.

No ha sido posible, con los casos tratados en el asilo de la Magdalena, hacer análogas constataciones, tanto por lo difícil y delicado que es practicar investigaciones de esta in. dole en nuestra poblacićn civil, en aquella tan llena de prejuicios y pudores que integar la clientela particulatr, cuanto porque-y este hechoes consecuencia directa del anteriortodos los casos llevados al asilo para ser tratados, han ingresado en un período muy avanzado de la entermedad y cuando los síntomas paralíticos y mentales imponían por sî solos el diagnóstico. La familia generalmente lleva al paciente al asilo cuando ya es considerado incurable o cuando se ha hecho intolerable en su seno. 
De lo expuesto podemos concluír que la linfocitos is ra. quídea es indicio cierto de una alteracion patologica en la esfera del sistema nervioso, en especial cuando éste se halla bajo la influencia del virus sifilitico y que la intensidad de la linfocitosis traduce la proporcion en que este tejido ha sido afectadn. alcanzando su máximun de intensidad y frecuencia en la sifilis cerebral y en la parálisis general, esto aun en ausencia de síntomas clinicos u objetivos de parálisis, excepto la anisocoria, lá rigidez pupilar, y el signo de ARgYr,LROBERTSON.

Nada hemos de decir aquí acercá de las teorías que pretenden explicar el origen y mecanismo de migracion de esos linfocitos en el líquido céfalo racuídeo, entre las que están la hematogena, de Nisso y lat histibgena de Fischrer, por no apartarnos mucho del temat que venimos desarollando, $y$ además porque algo hemos dicho sobre el particular en páginas anteriores. Diremos sólo, con Szriscors que la pleocito. sis es lat expresion de una periartertis cobobrespinal, generalmente de naturaleza sinlitica; habiendo FISCHER, Nisst. Alzheimer y Mexiar hallado estos elementos (células redondas y células plasmáticas) no sólo en las leptomeninges y plexos coroides, sino tambien en el espesor de la corteza cerebral, en los espacios perivasculares y alrededor de ellos, todo esto en diver'sosicasos de $P^{\text {p }}$. G.

Aun cuando alyunos investignalores germanos, entre los que se cuenta KAIKA. no ven estrecha riacion entre el grado de linfocitosis y la arudez. (Monicidad o intensidad del proceso (tabes, purálisis peneral, sifilis cereblal). esto queda indirectamente (lesvitualo por muchas y concluyentes observaciones, que demuestan que ese paralimmo existe, siendo más manifiesto en los casos agudos; toda vez que la infección sifilítica es nua cansa nosngénicá que determina el aumento de las células en el lícuiclo céfalo raquídeo, como expresión de la reacción meningea.

Respecto al numento de la albúmina en el líquido céfalo raquiden en las diversas formas de neurosftilis y $a n$ especial en la $P . G$, alcanza cratras eonsiderables. Podemos decir que está aumentada en general en todos los procisos infecciosos, agudos o crónicos, de 0.60 a $1 \mathrm{gl}$. y más, aumento que recae principalmente sobre las globulinas. La investigación de es- 
ta Gltina tiene mayor interés clinica que la de las aluaminas totales, y se investiga segun las reaciones de NONNE al sul. tato amónica, la de I’ANIY al ácido ténico, la de Ross Jonfs, etc. Lis sicrmifactiva el hecho dis que el tratanuiento antisifi. lítico, según comprobación de $\mathrm{R}_{\mathrm{H}} \mathrm{H}$ en varlios casos estudiados, no atectaba en lo nenor la cantidad de albumina.

Winat, Silian y Ravaud, afirmaban en 1903 que habid que consictelar a parte el ammento total de albanina y el de las globulinas y seroalbamitas, determinables por piecipitáción con el sulfato de magnesia. Resultados análogus obtuvierOn HENKEL y MrYir.

Se ha empleado, pala lograr esto, distintos procedimientos, tales como el de Cimbal para separar las globulinas de las albuminas, determinando después su canticlad sepaltadamente por el método KJEI.DA IIx, utilizando solución sat turáda de sulfato ambnicoque precipita en media satuación, globulinas y nucleoalbuniuas; con lolque se consigue separialas así de las albúminas (Nissi., Schumm, Aper. NonNi) reaccion está conocida con el nonlure de "réncoión de la fáse $I$ ".

No insisteremos sobre las diversás reacciones que se emplean para detenninar la cantidad de globulinas en el hiqui. do céfalo raquideo, entre las que mencionaremos la de RossJonis, Nonne Aprit, Panir, Noguchy y la del cluriro de mercurio subtosalicílico (de grandr valor en las meningitis tuberculoséts).

Entre nosotros, la más empleada es lá de Ross Jones, que consiste en la superposicion de 0.1 a 0.3 cc. de sulución Saturada de sulfato de amonio sobre una cantidad igual de líquido cerebro espinal (con formación de anjllo opricon en la zona de contacto, en los casos positivos); muy parecida a la de NonNe Apria, jelo tal vez núls sensible. Menos usáda entre nosotros es la rarcion le Pandy, a base le solución concentrada de ácido curbólico.

Es oportuno recordar que en la P. G. las abluminas y las globulinas están aumentadas, pero con preclominio del aumento de estas ultimas (glolulinas); en tanto que en la epilepsia ocurre locontrario, pues el aumento de proteínas se hace a expensas de la albamiua. Se ha podido determinar, además, que existe un aumento paralelo al de la liufocitosis en la P. G. (Sikmeri.ing. Dricoubaix. Hickel).

Su comprobación y dosaje es, junto con la determinacion de lá pleocitosis, de un gran valor diagnostico en las enfermedades metasifíticas, siempre que se determine me- 
diante reacciones sensibles como las que hemos enunciado $y$ estando, como casi sitmpre ocurre, en harmonía con los re. sultados de la R. W.

Mencionaremos también entre las investigaciones de or. den químico, aquella que se refiere a la determinación de la cantidad de glucosa en 1. c. r. Nos limitaremos a decir que puede investigarse con lá solución FrHLing; indicando cuando no hay rediccion, la presencia de una meningitis supura. da, puesto que en esos cásos la glucosa está notablemente disminuída o ansente. Entre los métodos cuantitativos, los más exactos son el de Lewis. Benedit y el de For.in-Wu, empleados también para la determinación de la glicemia.

Está demostrado, en lo que respecta a la neuro-síflis y en especial a la P. G., que la glucosa no sufre modificación cuantitativa. Hompkins encuentra una menor cantidad de azácar en 1. c. r. de los siflíticos que en otras concliciones, excepto meningitis epidémica; pero los trabajos de Lrvinson y Strouse no demuestran alteración de ella en l. c. r. luético.

Entre los métodos de investigación físico químicos, mencionaremos en primer lugar, ann cuando su importancia diagnóstica es relátiva debido a dificultades de técnica, el que se refiere a la determinación de la concentración de $\mathrm{Hi}$. drógeno (P. h.); el principal de los cuales es el de Levvy. Rowntren Marriojt. Pala la reserva de álcali, el más exacto es el método de VAN Sijikr.

Reacción de Lánge al oro coloidal.- Es esta una prueba muy sensible y de gra: valor en el diagnostico de diversas formas de neurosíflis, así como también pára diferenciar el tipo de meningitis.

Requiere en su confección uná precisión y un cuidado extraordinarios. Omitimos, en el deseo de ser breves, detalles de técnica. Recordaremos simplemente que se usan 10 tu. bos de prueba químicamente limpios, de reacrión neutia, en el primero de los cuales se vierte 0.2 cc. de líquidocerebroespinal, al cual se le añade 1.8 cc. de una solución salina al $0.4 \%$. Eu cada uno de los otios tubos se vierte $1 \mathrm{cc}$. de la mismá solución; mezclando bien el eontenido del primer tu. bo y extrayendo de él $1 \mathrm{cc}$. que es colocado en segundo tubo; de éste se retira, támbiél, 1 cc. que se coloca en el tercer tubo; de éste 1 cc. al cuarto, y así sucesivamente. Así se obtie- 
nen dilusiones progresivamente crecientes, en esta forma: $1: 10,1: 20,1: 40,1: 80,1: 160,1: 320,1: 640,1: 1280,1: 2560$, 1:5120. Finalmente, a cáda tubo se le añade $5 \mathrm{cc}$. de solución de oro coloidal, observandose después los cambios de coloración que en ellos se produce una hora después, aunque es más prudente aguardar hasta 24 horas. Los resultados se expresan gráficamente por una curva o en nümeros; así, O significa ningún canbio, 1 cambio al rojo azulado, 2 cambio al violeta, 3 al azul, 4 al azul pálido y 5 al claro; de consiguiente, tomando como ejemplo la curva paralítica que es. tá representadu por 5,555'500,000, significa que los primeros cinco tubos o las dilusiones de $1: 10$ a $1: 160$ han sido com. pletamente descolorados, mientras que los altimos cinco no han experimentad o cambio alguno, permaneciendo rojos.

Ofrecemos a continuación ejemplos de tres curvas típicas: una de un caso de sifils cerebral, otra de un caso de tabes, y una tercera de un cáso de parálisis general.

La Reacción del Mastic, descrita por Cutring y estudiada y perfeccionada por Emanufl, Harka y Jaconsthaly EsKuchen, váría según el tipo de la enfermedad del sistema nervioso central. Su técnica es delicadal y bastante compleja, algo parecida a la anterior en algunos detalles y como ella se expresa su resultado en diagramas, habiendo dos curvus principáles: la luéticá y la meningítica.

Lal reacción del benjuŕ coloidal, demostrada por WarNoCK, es muy reciente y sus resultados muy inconstantes.

Estas dos altimas reacciones no siempre dan resultados bien definidos. De las reacciones coloidales, la de Lange es sin duda de nayor valor diagnostico por la nitidez de sus resultados.

La reacción de Wassermann en $l$. c. $r$. es bien conocida tanto en su técnica, como en su indiscutible importancia diagnóstica. Su positividad nllí, es casi en todos los casos indicio cierto de una lúes cerebroespinal. Acerca de sus resultados en lás diversas formas de neurosífilis, así como el paralelismo y harmonías que estos guardan con algunas delas otras reacciones en especial con la linfocitosis y con las globulinas, nos ocuparemos en breve.

En cuanto a la reacción de las hemolisinas de Weil Kaf: $k a$, es igualmente importante y sensible, y los datos que sumi- 
nistra, son por su precocidad, de positivo valor en los diversos procesos meníngeos y de consiguiente en la lues cerebral y en la parálisis general.

Los autores citados, WhIL y KaFka, demostraion la presencia de hemolisinas (amboceptor y complemento) en el líquido céfalo-raquídeo en afecciones del sistema nervioso con compromiso meníngeo. La presencia de ambo ceptores hemolíticos y complemento está explicada, según estos autores, por un aumento de lat permeabilidad meníngea y de los capilares cerebrales, hecho constante en las diversas formas de neurosifilis, especialmente en la P. G. Estas hemoli. sinas, ausentes en un l. c. r. normál, tienen un gran significado diagnóstico y pronóstico.

Fischer ha comprobado la exactitud de las teorías de Weil y Harka, con las que se halmoniza la de Poktzl, quien sostiene que eu la $P$. G. se produce una mayor permeabilidad vascular en los capilares cerebrales y meníngeos, originada tanto por la presencial de los espiroquetes en los elementos nerviosos, como a factores constitucionales que le hacen más sensible. Pásan así a la sangre, a más de los amboceptores hemolíticos, que la reacción de las hemolisinas pone en evidencia, otras sustancias albumonoideas que actuan como catalizadoras de las toxinas producidas por el espiroquete, que fávorecen a éstás, xefotzando su acción des. tructora y progresiva del tejido y células nerviosas. Todo esto determina en el paralítico general una gran disminución de las reacciones inmunológicas, de los necanismos defensivos y de lá reactividad celular.

Ahora bien; está demostrado que bajo la acción del tratamiento málárico de la P. G., se aumentá el poder de la acción defensiva del organismo; hecho observado por Plate en sus casos de P. G., tratados por la fiehre recurrente y traducido por el aumento linfocitario que se observa durante los accesos febriles, lo que se ha podido constatar entre nosotros.

Siendo las hemolisinas las primeras y las que más rápidamente se modifican bajo la acción de los agentes piretógenos, PoExzl ha demostrado que las remisiones observadas en el curso del tratámiento malárico y a consecuencia de éste, dependen de la disminución o desaparición del proceso catalítico, siendo la reacción de las hemolisinas un indicador de la intensidad de este proceso catalítico.

De allí la importancia de esta reacción.

Para concluír, mencionaremos las reacciones de Sachs- 
Georgi, de "sigma" de DrEyer y WARD, y de Ka HN, que son reacciones de floculación de coloides, empleando como antígenos, extractos alcohólicos de corazón colesterihizado.

Reaccion de Sachs.Georgi.-Reacción de floculacion, empleando como antigeno extracto alcohólico de corazón de buey, colesterinizado.

Reaccion "sigma" de Dreyer y Ward-Semejante a la anterior, pero empleando diferentes cantidades de suero pa*a hacerla cuantitativa.

Reacciou de Kahn.-Análoga a las anteriores, de las que se diferencia Gnicamente en que empleáa antigenos más ricos en lipoides.

La sensibilidad de estas tres reacciones, a unque grande, no iguala a la reacción BORDET. WASSERMANN.

Vamos a exponer a continuacion, sumariamente, las conclusiones recogidas por Cornaz despues de detenidas y pacientes investigaciones, acerca de lá frecuencia, intensidad y periodos en que las más importantes y demostrativas de estas reacciones se presentan en el líquido céfalo-raquideo en las diversas formal de neuro sifilis.

Las estadísticas bastante considerables de Cornaz, es. tán basadas en el estudio de 354 casos (CORNaz. "Study of Cereluroespinal Fluid in Diff. Periods of Syphilis", "Joumal of Nerv. \& Mental Dis.n, April, 1919), cuyos resultados concuerdan con los obtenidos pur Mouriz en trabajo más reciente ("Estudio Serologico de la Neurositilis", 1924).

Las cifras que expondremos a continuacion evidencian una vez más la importancia de hamonizare interpretaren conjunto los datos proporcionados por estas diversas reacciones, puesto que ninguma de ellas, aisladamente, cualesquiera que seá sul precisión e importancial, nos autoriza a formular conclusiones diagnosticas defunitiras.

Lus resultados obtenidos por Cornaz en ese crecidon número de casos, fueron los siguientes:

1. ${ }^{\circ}$-En sifilis primaria, es decir en sujetos portadores de chancro duro, sin manifestaciones secundarias, en un total de 76 enfermos, todos puncionados antes del comienzo del tratamiento, 24 de los cuales presentaban $R$. W. negativa en la sangie, al hacer la punción raquídea se halló en éstos un promedio de sólo 2.4 linfocitos por mm. 3, mientras que 
esta cifra subio a un promedio de 6.1 linfocitos en los 52 en. fermos restantes todos los cuales presentaban yá en la sangre una R. W. positiva. En 59 de estos enfermos se iuvestigo la $R$. Wr. en el líquido céfalo raquideo, en 58 delos cuales fué negativa, con sólo un resultado positivo, en un enfermo que era portador de un WassirmanN sanguineo fuertemente positivo y que ya presentaba ma linfocitosis de 9 elementos por mm. cúbico).

La albuminosis raquide:a investigada por el ácido frico, de acuerdo con la escala de Bi,och, permaneció generalmente dentro de lo normal (0.2 a $0.3 \mathrm{gr}$. por mil). No se halló, en este periodo de la sífilis, paralelismo algumo entre la cantidad de albumina y el número de linfocitos. La reaccion Nonire A PEI.T para las globuliuas sicmpre resultó negativa en esta fase de la enfermedad.

$2 .^{\circ}-\mathrm{Al}$ apritecer las manifistaciones de sifflis secumdaria

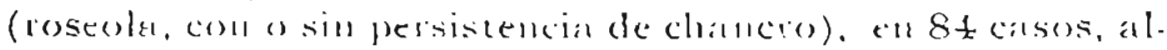
gunos puncionados antes del tratamientos se hallo un pro. medio de 8.2 linfocitos por mm. 3, m $40 \%$ de los cuales presentaron cifras más altas. la R. W., positivatu lin sangre, en tolos los casos. En 71 casos (1) los 84), se invergtigo la R. W. en ell. cir..obteniéndose resultadn positivo en $10 \mathrm{cn}$ sos, en los cuales-dato de rian interés-el promediodelintocitosis raquílea subio a 17.1 gor mm. 3; mientras que enlos 61 casos restantes en los cuntes la R. WV. mquidea fué negali. va, la linfocitosis sólóalcanzó un promedio de 5.6 p. $\mathrm{mm}$. 3, cifra que está por delsajo del nuáximmon normal aceptado.

La linfocitosis más altá observala en esha fase de lá enfermedad fué de 67 elementos pot mm. 3, wh un caso con $R$. W. raquidea positiva. Esto evidencia claramente el parale. lismo existente entre la linfocitosis racpidea elevala $\mathrm{y}$ la intensidad y frecuencia de lá R. W. positiva en el líguido céfalo-raquídeo.

La tasa de aibrnina sufrió aumento en algunos casos, en el $45 \%$, en los que la linfocitosis era clevada; pudiendo, en cambio, ser positiva la R. W. raquídea en casus con canti. dad normal de albúnina.

En 25 casos que presentaban placas mucosas, sin roseola ni condilomas, solo se hallo comodato de interés $24 \mathrm{R}$. W. pusitivas en la sangre, mostrando el l. c. r. una linfocitosis exígua, con un promedio de 5 elementos pormm. 3 (menor que en la roseola) y una sola R. W. positiva.

En 30 enfermos con grandes condilomas, sin rostola ni 
placas mucosas, la $R$. W. sanguínea fue positiva en todos los casos: $100 \%$. La linfocitosis raquídea apenas alcanz6 un promedio de 5.1 , con R. W. positiva en 4 casos.

En 65 enfermos afectos de sifilis latente de larga duracion, muchos tratados anteriormente, y otros cuya sífilis, largo tiempo ignorada, había sido ocasionalmente descubierta, sin signos de síflis nerviosa, los resultados fueron los siguientes: En aquellos en los que la $R$. W. Sanguínea fue positiva $(70 \%)$, la linfocitosis raquídea aumentó en el $40 \%$ de los casos, mostrando un promedio de 8 for $\mathrm{mm}$. 3, mientras que en aquellos con $R$. W. negativa en la sangre, la lin. focitosis fué sólo de un promedio de $4.7 \mathrm{p} . \mathrm{mm} 3$. La $R$. W. raquídea fué sólo positiva 5 veces en 64 casos examinados $(7.8 \%)$, y en un caso con R. W. negativa en lá sungre dió re. sultado positivo en el 1. c. r., en el que se trataba de un antiguo caso de sífilis que había sido largamente tratado.

Diremos, de paso, que este hecho viene al reforzar lo que hemos inanifestado en páginas anteriores, algo que hechos clínicos recientes se han encargado de demostrar. En lo referente a la incapacidad de los agentes farmacológicos clásicos (salvarsanoterapia, etc.) para modificar las alteraciones meningo encefálicas, aun las más discretas o aquellas que tan sólo se revelan por alteraciones del líquido céfalo.raquídeo.

Esto sin referirnos con amplitud al hecho no menos gra. ve constatado por numerosos autores-y entre nosotros por el Dr. Honorio F. Den.Gado, con el material del asilo de Mag. dalena-del etecto inhibitorio que la salrarsanoterapia pro. longala ejerce sobre las reacciones tavorables que la malarioterapia iletermina siempre en los casos de P. G. no tratados anteriormente por el arsénico.

Todos sabemos que mientras las manifestaciones exter. nas, características de los dos primeros periodos o tases de la síflis, y auu las reacciones serológicas ( $R$. W. sanguínea), son substancialmente modificadas por la tarmacopea anti. luetica, permanecen inalterables las reacciones propias al compromiso de los eentros nerviosos. Frente a esto-yalo dijimos e insistimos en repetirlo-sólo puede la acciśn de la malaria artificialmente inoculada, de cuyo complejo mecanismo de acción nos hemos ocupado en páginas anteriores.

Todos estos hechos se irán reforzando con los suscintos d a tos estadisticos que vamos a concluir de exponer, toda vez que ellos provienen de fuentes cuya veracidad y exacti. tud cientificas están ampliamente galantizadas. 
3. - Sifilis terciaria (gomas y ulceraciones).-Se practic6 la puncion raquídea en 55 enfermos, $77 \%$ de los cuales presentaban una $\mathrm{R}$. W. positiva en la sangre. Promedio de linfocitosis, 7,1 por $1 \mathrm{~nm}$. 3, aumentada en el $37 \%$ de los en. fermos, sensiblemente igual en los casos con R. W. positiva o uegativa. Se obturo R. W. raquidea positiva en 3 casos, uno de los cuáles con $R$. W. negativa en la sangie. Hubo hiperalbuminosis discreta en el $40 \%$, comenzando yat a manifestarse un ligero paralelismo entre la albuminosis y la pleocitosis.

$4 .^{\circ}$-Siflis cerebral y meningo-mielitis.-Seis cásos estudiados, cuatro de los cuales $(66 \%)$ con $\mathrm{R}$. W. positiva en la sangre. Pleocitosis considerable en el $100 \%$ de los casos, con el elevado promedio de 51 linfocitos por $\mathrm{mm}$. 3, uno de los cuales presento una linfocitosis elevadísima de 235 elementos, arrojando los otros cinco casos un promedio de 15 p. $\mathrm{mm} .3$.

La R. W. fué positiva en todos los casos cruel l. c. r., aun en aquellos dos casos $(33 \%)$ en los que la $R$. W. resulto negativa en la sangre. La cantidad de albúmina pas 6 de 0.6 por ciento, alcanzando en un caso, en el de la elevada pleocitosis, $1.5 \mathrm{gr}$. por cientu.

5."-Tabes.-Examen de líquido cétalo-raquídeo practicudo en 13 en ermos, 9 de los cuales con R. W. positiva en la sangre, $69 \%$. El promedio de linfocitosis raquídea fué de 30 .p. mm. 3, a umentada en 11 de los casos (en el 85\%). La. R. W. en el 1. c. 1 , resultó positiva en $\Theta$ de los 13 casos no tratados, pero después de una serie de neusalvarsán, resultó positiva en los 13 entermos (100\%). Promediode albŕmina, $0.6 \mathrm{gr} . \%$, aumento proporcional al de la linfocitosis.

6. - -Paralisis Gencral Progresiva.-Observaciones que sølo han podido realizarse en 4 casos. Todos ellos con $R$. W. positiva en la sangre $(100 \%)$. La linfocitosis en el 1. c. r. alcanz6 un promedio de $28 \mathrm{p} . \mathrm{mm}$. 3., numentada en tc. dos los casos, con un aumento proporcional de albúmina: $0.8 \%$, ulcanzando un máxinun de $1.5 \mathrm{gr}$. por ciento en un cáso cuya linfocitosis fué 12. Además, en otro enfermo esta albuminosis fné sólo de $0.8 \mathrm{gr}$. \% para una linfocitosis de 51; lo cual muestra que el paralelismo entre la cantidad de alba. mina y el número de linfocitos por $\mathrm{mm}$. cribico en el l. c. r.. dista mucho de ser constante, lo contrario de lo que ocurre entre la intensidad de la $\mathrm{R}$. W. raquidea y la linfocitosis.

Vamos, a continuación, a tabular estos resultados de 
Cornaz que, como hemos manifestado, se refieren al estudio de 354 casos:

\begin{tabular}{|c|c|c|c|c|}
\hline Faz de la eafernuedad & $\begin{array}{l}\text { Promedio } \\
\text { delinfocitos } \\
\text { en el l. c. r. }\end{array}$ & $\begin{array}{c}\% \text { de casos } \\
\text { con allmell- } \\
\text { to linfocita- } \\
\text { rio }\end{array}$ & $\begin{array}{l}\text { R. W. en el } \\
\text { 1. c. r. posi- } \\
\text { tiva, por } \\
\text { ciento }\end{array}$ & $\begin{array}{c}\text { Reaccion } \\
\text { Wasserman } \\
\text { en la san- } \\
\text { gre. positi- } \\
\text { va, } \%\end{array}$ \\
\hline R.W. + Chrincioduro & 6.1 & 35 & 1.6 & 68 \\
\hline R. W.-Chrnciodmo & 2.4 & 8 & 0.0 & 68 \\
\hline Rosevla................... & 8.2 & 40 & 14.0 & 100 \\
\hline Placals mucosals........ & 5.0 & 32 & 4.0 & 96 \\
\hline Grandescomiliom.... & 5.1 & 27 & 13.0 & 100 \\
\hline R.W. + Lueslatente & 8.0 & 40 & 8.8 & 70 \\
\hline R. W. - Líes latente & 4.7 & 30 & 5.0 & 70 \\
\hline Sifilis hereditaria..... & 3.9 & $\mathrm{O}$ & 5.0 & 100 \\
\hline Sifilis hereditaris..... & Despu. del $t$ & tratamiento: & 16.6 & 100 \\
\hline Sifflis terciaria & 7.1 & 37 & 6.6 & 77 \\
\hline Meningitis sifiliticat. & 51.0 & 100 & 100.0 & 66 \\
\hline Tabes............. & 30.1 & 85 & 69.0 & 69 \\
\hline Tabes............... & Despu. del $t$ & tratamiento: & 100.0 & 69 \\
\hline Paralisis general. & 28.0 & 100 & 100.0 & 100 \\
\hline
\end{tabular}

Estas observaciones han permitido confirma la frecuencia y precocidad con que se propaga a las meninges la infección sifilitica como lo prueban las cifras expuestas por Dino (Revue d'Urologie, 1914), y por C'ornaz (Jour, of New. and Ment. Dis., 1919) las que demuestran que $36 \%$ de los casos de chancros duro estaba ya aumentalo el nirmero de linfoci. tos en un momento en el cual las manifestaciones cutáneas y mucosas no habian a frn aparecilo.

Es, pues, la linfocitosis raquidea la primera en delatarel incipiente compromiso meningeo en un sitilítico cuyo líquido céfalo-raquideo es aparentemente normal en lo que respecta a la tasa de allúmina y a la fijación del complenento. Y es que tan pronto como la gifilis selocalizat en el sistema nervioso central, el líquido céfalo raquídeo experimenta inmediatas moditicaciones, ho que es de gran valor para el diagnóstico y parat el control del tratamiento.

Sin embargo, la reaccion de Wasseruann ell el 1 . c. r. debe hacerse sistemáticamente $p o r$ :a fiecuencia con que resuta positiva, revelando un compromiso meningeo, álan con $R$. W. negativa en la sangre; hecho, por lo demás, frecuente como lo hemos indicado.

Datos igualmente importantes suminista la glubulino- 
sis especialmente en lá P. G. y hemos visto cuán sensibles son las reacciones coloidales especialmente la de LANGE.

Bajo lo ácción de una terapeńtica activa en los casos incipientes a que nos estamos refriendo, la linfocitosis tiende a desaparecer (a semejanza de lo que ocurre con los hemoli. sinas cuando se usa la piroterapia). Pero cuando a pesar del tratamiento específico se mantiene constante, puede este ser un indicio de que el caso en cuestion se encamina hacia una tábes o hacia una P. G. De consiguiente, por el estudio sistemático y precoz de la linjocitosis raquídea en casos de síflis reciente aparte de las alteraciones pupilares que pue. den existir tempranamente-, y, por su persistencia, es posible establecer un diagnóstico precoz de una P'. G. que comien. za y detenerla en su marcha progresiva por la inmediata aplicacion de la piroterapia, en especial con la técnica de WAGNER-JAURIiGg; lo que, , como homos visto en otra sec. ción de este trab jo (Cap. III,)-ha sidoverificado yá señaladamente por KYRLa y Bering.

El valor de estas diversas reacciones se acrecienta, cuan. do se interpretin sus resultados en conjunto, más que considerándolas alisladamente, en especial cuando van complementadas por la $R$. W.

Ellas deben, desde luego, estar en harmonía con el cuadro clínico del sujeto a fecto o por lo menos con sus antecedentes nosológicos, toda vez que algunas de ellas no son específicas pudiendo prescntarse $\in$ notras afecciones. Así, por ejemplo, la linfocitosis raquídea es también más o menos ele. vada en algunas otras entidades nosológicas, entre las que mencionaremos-a parte de la neurosifilis-a la meningitis tuberculosa, la enfermedad del sueño (SPrinayer y MOTx), polionnelitis, encefalitis epirennica, meningitis cerebroespinal, y también ell el herpes zoster (Schal,Ler: Herpes Zostes and Cerebrospimal Fluid). Descontadas estas afecciones cuyas características clínicas las ponen al márgen de un grosero error diagnóstico, lá pleocitosis raquidea resulta siempre un signo precoz de una siffis nerviosa hasta entonces ignorada o simplemente sospechada; esto lo repetimos, en har. monía con la $\mathrm{R}$. W. y la globulinosis.

Esta harmonizacion, esta concordancia de resultados de estas diversas reacciones es indispensable cuando se quiere hacer un diagnostico temprano y preciso. Pormncha que sea la importancia que aisladamente tienen, la no especificidad de algunas hace que su poder demostrativo se reduzca. 
cuando se trata de hacer diagnóstico diferencial entre ufecsiones neurosifiliticas semejantes.

Tal ocurre, por ejemplo, entre la linfocitosis y la globulinosis en el 1. c. r. Así, mientras la primera puede presentarse en sujetos que habiendo sido infectados de síflis no padecen ninguna enfermedad nerviosa independiente de esta, la globulinosis tán sólo aparece en enfermos atectos de neurosíflis, nunca en enfermos con alteracion puramente funcional; tales como los neurasténicos, los histéricos, hipocondrícos o epilépticos (en estos álimos hay aumento de albaminas pero no de globulinas), que a más de estas entermedades han sido infectados de sífilis y en los que jamás aparece positiva la reacción Ross-Jonlis, NONNE-APELT, etc. (para globulinas), en ausencia de neurosífilis.

Estos hechos tienen por esto un enorme valor oportunis. tá todá vez que ellos deciden la necesidad y urgencia de instituir, fiente a un caso dado la sífilis nerviosa, el procedimiento curativo que motiva este trabajo, es clecir lo piroterapia y muy en especial la técnica de Wagner von JaUREgG.

Lo que acabamos de exponer respecto a la linfocilosis y globulinosis es aplicable al "valor de la $R$. W. en la sangre $y$ en el liquido céfalo-raquídeo" en la neurosífilis, y cuya fiecuencin en sus diversas fases se puede apreciar en el cuadroque resume las experiencias de Coirnaz (Véase pág. 133 del Noant.)

A pesarde que tampocoesta renccion es específica, su utilidal y valor en neurosífilis es considerable. Una R. W. positiva en l. c. r. es-salvocasos de lepra o beri-beri perfectamente diagnosticables-patonogmónica de la síflis nerviosa.

HaUptaAn y Hossia refiriéndose a la constancia con que se muestra positiva en la P. G. án empleando muy pequeñas cantidades de liquido $\left(0.02{ }^{\prime} c\right)$, utilizan ésta sensibilidad como elemento de diagnóstico diferencial con otras va. riedades de neurosifilis en la que también es positiva lá reaccion, pero solo empleando cantidades nucho mayores de líquido $(0.04$ a 0.08 cc. $)$

Sin embargo, está demostrado que la intensidad de la reacción depende más de la actividad del proceso que de su naturaleza ovariedad; desempeñando rol importante la lo. calización de las lesiones. Cuando el proceso sifilítico no ha envuel to el sistema nervioso, la reacción es negativa án empleando cantidades considerables de líquido; e inversamente muchos casos de neurosifilis muestran un abundante pleocitosis y una R. W. positiva en el 1. c. r. mucho tiempo antes 
de que se hagan ostensibles los signos neurológicos o psiquiátricos.

Gennerich, reáfirmando $1 a$ importancia de estos hechos ha constatado la $\mathrm{R}$. W. en la sangre, en el $95 \%$ de los casos de parálisis y de los de tabo parálisis; y en el 60 a $70 \%$ de los tabéticos y mieliticos, hasta 10 años después de la infección; siendo menos frecuente despurs de 10 años.

El mismo auttor (GENNERICH), refiriéndose a la frecuencia de la reacción Wassermann en el líquido céfalo-raquídeo, llega a estás conclusiones: en los casos de "tabes" es "débilmente positiva" y está "sólo" en los "estados iniciales", haciendose "negativa" en todos los "casos avanzados" (por ngotamientodel poder reaccionál). En la "parálisis general" y en la "tabo-parálisis" la encuentra, el autor citado, "fuertemente positiva" en la gran mayoría de los casos; y aquellos que la presentan positiva "en menor grado" (coul) 0.5 a 1 cc. de líquido), "son ruros" y constituyen verdauteras excepciones.

Esta marcada diferencia en cuanto a la frecuencia con que se presenta positiva la $R$. W. raguídea en la tábes y en la $P$. G., de gran valor diagnóstico, fué primero comprobada por Pla ox y después por Śtrektz y por Nonnk, entre otros. Estos resultados se hacen más difiles de interpretar en los casos de tabo-parálisis.

Encuanto al "valor diagnóstico" de la $R$. W. "enl la sangre", es muy limitado en lo que respecta a la sifilis nerviosa, por el doble hecho de que cuando se presenta positiva no implica "necesarianente" que exista compromiso de lado del sistema nervioso, indicando simplemente la actividad de la infección sifilitica (descartadas las otras pocas a fecciones que exhiben una R. W. positiva), actividad que se atenta en los periodos de latencia; y porque, de otro lado, es frecuente ob. servar casos clínica y serológicamente comprobados de síflis nerviosa, con reacción de Wassermann, en la sangre, persistentemente "negativa".

De consiguiente, es indispensable aunar, a los datos suministrados por una $R$. W. sanguinea, los que se obtengan de la $R$. W. en el líquido céfalo-raquíeeo; siendo necesario con frecuencia recurrir a la reactivación del proceso, paráa obtener resultados precisos.

Finalmente, debe tenerse presente en el diagnóstico de la sífis nerviosa que está reacción en el líquido céfalo-raquídeo es una prueba monosintomatica. De consiguiente, sus resul- 
tados deben ser siempre interpretados de acuerdo con otras pruebas clínicas y de laboratorio. Sólo a si logra remos obtener de estas diversas reacciones todo el valor diagnostico y pronóstico que en reálidad tienen, cuando se las interpreta en conjunto, procurando hatronizar sus resultados.

Tal es, en síntesis, la manera como se comportan estas "cuatro reacciones": la R. W. en el líquido céfalo-raquídeo, la reacción Ross-Jones (reacción "fáse I". de Nonne) para las globulinas, y la pleolinfocitosis, "en las diversas modalidades" de "sítilis nerviosa", y el valor que su presencia o ausencia en la-sang re o en el líquilio céfálo-rálquídeo tiene para precisar un diagnóstico clínicamente dudoso y para eviden. ciar una "parálisis general" en sus comienzos.

Si hemos insistido sobre lo que acabamos de exponer, es porque, a nuestro juicio, ello reviste una enorme inportancia no sólo para "fines de diágnóstico", sino también desde el punto de vista "médico-social".

En efecto, lejos está de comstituír éstos un simple acrimu. lo de datos estadisticos de nerat especulación científica, des. provistos de interés práctico. Para nosotros signifaca mucho más; significa que si bien es cierto qae la infección siflílicát deja un amplio márgen entre la fecha de la infección y aque. lla en que aparecen los primeros sintomas clínicos del proceso menúngo-encefálico final (tábes, patálisis general), en cámbio las reacciones humorales y en especial las del liquido céfalo-raquídeo son de una precocidad que no puede nenos de impresionar, comoconsta en las numerosas estadísticas existentes, en especial las de Fildes y las de Cornaz, a las que acabamus de referirinus.

El doble hecho comprobado de lo tardio de la aparición de los síntomás clínicos - comienzo manitiesto de la entermedad que ocurre a los 3 o a anos y arn a las 10015 de la infección original-y la precocidad con qué se toman positivas las reacciones serologicas, en especial la linfocitosis céfaloraquídea y las reacciones coloidales, nos está indicando, con evidente claridad, que el enfemo inteligente y cuidadoso de sufuturo, y más ár el cínico sagáz tienen an te sí un amplio márgen salvador, un lapso siempre suficiente para instaurar oportúnamente un trátamiento antiluético discreto que, asoo iado alque venimos preconizando para los casos-confirma- 
dos o presuntos de "párálisis general progresiva", y de lúes del sistema nervioso en general, conduciránal enfermoa una cura. cion definitiva, sin exponerlos a las inconstancias inevitables que todotratámiento tiene cuando es tardíamente instituído.

Si habitualmente las cosas no ocurren hsi, ello se debe a las difcultades con que los médicos tropiezan diariamente para hacer más extensiva la prácticá de la punción raquídea, y la mayor reside en el enfermo mismo, quien rechazando la punción en sí por temores infundados, se opone a ella con tanta mayor firmeza cuanto más encumbrada es la posición social que ocupa. Y es así cómo, por puerilidad de un lado, y de otro - en ocasiones - por falta de conviccion o de autoridad del médico, se deja de lado el estudio cito químico del líquido cefalo-raquíleo; una rutina que tan interesantes revelaciones y sorpresas ofrecería al clinico y tantos infortunios evitaría al enfermo, a la tamilia y a la sociedad.

De consiguiente, estos conceptos, a parentemente sin conexión con el tema del presente trabajo, tienen con el, en realidad, wna doble relación.

Una de ellas se derival de un hecho de importancia vital para el enfermo, y es la absoluta posibilidad de formular un diagnóstico precóz cuando se establezca, como lo acabamos de decir, "el sistemático análisis cito cuuímico del líquido cé. falo-raquídeo de todo sujeto que ha contraído una síflis", y que por esa u otra causa llega a un consultorio médico en busca de tratamiento o de consejo, aun en ausencia de toda complicación neuro-encetálicá.

Procediendo así se conseguiría, en primer lugar, reducir el enorme material con que el treponema elabora lenta pero fatalmente, paralíticos generales. Redazcase el namero de si. filíticos instituyendo un a propiado tratamiento, precóze intensivo y se teducirá el porcentaje de los que, con la complicidad de cualquier otro fictor eficiente - sensibilidad constitucional del sistema nervioso, alcoholismo, traumatismos, surmenrge-, irán más tárde, cuando el cuadro de P. G. se haya desarrollado en toda su trágica elocuenciá, a ocupar una celda más de un Asilo de alienados.

Cierto es que para estos desgraciados, víctimas ciegas de indolencias propias y ajenas, para quienes hasta hace poco no había otra esperanza que la piedad de la muerte, existe hoy el recurso alentalor con que WagNer-Ja vergg y sus seguidores hán cambiralo tan notablemente el pronostico de .estos enfermos. 
Pero es precisamente por esto que insistimos en sostener que ni tan halagndores resultados terapéuticos se consiguen con el método que nos ocupa en priralíticos generales avánzados, en los que tantas y tan graves alteraciones ha deter. minado la enfermedad, cuáuto mas crecido no sería el poicentaje de curaciones que con esta misma técnica se obtendría si con investigaciones más prolijas y tempranas se pudiera desenmascarar la enfermedad en sus primeros pasos, cuando casi tan s6lo las reacciones bumorales son el "\{unico indicio" de lo que há de ocurrir más tarde.

Esto no quicre decir que incurramos en el lugar combnde enfatizar las conveniencias, de indole puramente profiác. tica, de que se eviten las ocasiones de contrigio, o se institu. ya el tratamiento habitual tan pronto cono la infeccion se ha declarado; punto es este que está en la conciencia de todo médico y án del páblico en general. Nos queremos referir, finicamente, a aquellos cásos de síflis más o menos recientes que tratados o 116 por el mercurio y compuesto arsenicales o bismutados, muestran desde muy temprano, por la especial concurrencia de diversos factores a los que hemos hecho ya alusión, una marcada tendencia a las localizaciones encéfalomedulares.

Opinamos que si estas serias localizaciones han comenzado a efectuarse de predisposiciones particulares del sujeto afecto y con la concurrencia de otros factores degenerativos y predisponentes, casi nadá podrá detener ya la evolución fatal del proceso y años más tarde, cuando el mal hay r echo hondos estragos en el organismo y en la mente del enfermo, habrá que apelar como ́nico recurso terapéutico a la acción curativa de las reacciones bio.químicas (proteínicas) y termogenéticas originadas por lá inoculación del gérmen malárico.

Con esto queremos siguiticar que si es cierto que cuando se ha hecho clínicamente evidente la P. G. todo tratamiento antiluético ordinario resulta ineficáz para detener la marcha progresiva del proceso (KYRL.e-BBRING) o aún para modificar los sintomas y que hay que recurrir con fundadas esperanzas de curación a la técnicá de WAGNer-JaUREgG; es no menos cierto que nada podrán, frente a un caso de sífilis reciente con tendencias a degenerar en un proceso meningoencefálico, en una tábes o en una $P$. G., los recursos farma. cológicos usuales, a un cuando no haya todavía signo clínico alguno propio de lá P. G., aún cuándo no hayá el más ligero trastorno funcional ni psíquico y sí fuicamente una altera- 
ción citológica reveladora, en el liquido raquídeo. En estos "cusos incipientes", como en los casos avanzados fracasarán necesariamente los recursos farmacológicos, los que en veces agravan la condición del paciente, precipitando incluso la aparición de la metalues-como lo ncreditan algunos de los casos que presentamos-, se impone entonces en estos como en los otros la aplicación del tratamiento piretógeno, especialmente al malárico.

Siendo por esto evidente que los resultados de esta aplicacion, serán tanto más lisonjeros cuanto mas temprana. mente se pongan ell prática. De allf que hayamos querido insistir sobre la importancia de la investigación sistematica da las alteraciones que sufre el l. c. r. en todo sujeto sifítico que se encomienda a nuestros cuidados.

Y creemos que procediendo así no sólo se hace lábor lógica y científica, sino que, poniendo al enfermo y poniéndose nosotros misnios a (ubierto de dolorosas sorpresas propias de una enfermedad que tan insidiosamente evoluciona, haremos atlemás habor de humanidad y depuración social.

\section{CAPÍTULO V}

\section{Casos tratados}

Ofrecemos a continuación la exposición de los casos tratados en el servicio del Dr. Honorio F. Delgavo, del Asilo "Víctor Larco Herrera", de Mágdalena, mediante la "Piroterapia", en la casi totalidad de los cuales se ha seguido la técnica de WAGNer von JaUREgG.

Desde el 24 de Febrero de 1921 - fecha en que se implan. t6 por primera vez entre nosotros y a ́n en toda América, este método de tratamiento - hasta el presente, ha sido puesto en práctica en todos los casos de neurosífilis que han ingresado al servicio. De ellos, of recemos treinta casos.

Para cumplic o completar la acción del "tratamiento ma. lárico", se ha recurrido, en ocasiones, a otros agentes termo. genéticos, especialmentecuando las condiciones físicas del enfermo han obligado a suspender el tratamiento.

Poresto, con relativa frecuencia, se ha recurrido al meto. do de Fizcher, y las inoculaciones de sangre malárica han 
sido en algunos casos intercalados con series de inyecciones de "nucleinato de soda" y "phlogetán".

La "tuberculina" no ha dado resultados que animen a continuar sa empleo. Resultados mucho más constantes se ha obtenidoconel uso de la "tifo-vacuna Besredka. Y en ningún caso se hat empleado la "técnica de Rosemblunı", por razones que en otro lugar hemos expuesto.

El "Bismuto-Yatren" se ha mostrada según experiencia recogida en el servicio, como una excelente coadyuvante del tratamiento malárico.

Añadiremosque la tecnica de WAGNer-JauregG no ha sido empleada entre nosotros de modo exclusivo en el tratamientode la Paralisis General, pues como se vera en las "Observaciooes" que a continuación exponemos, el tratamiento máárico ha sido aplicado también con buen exito en casos de "síflis cetebral", de "demencia precóz" y de "tabo-purálisis".

Observacion $N^{\circ}$ 1. - C. A., de 45 años de edad (al presen. te), inestizo, catolico, abogado, crisado. A la edad de 18 años contrajo la sífilis; el chancro fué curálo con aplicaciones locales. El paciente recibió poco después varias series de biyoduro de mercurio. A pesar de ello, por la naturaleza del sujeto, porlo incompleto del tratamiento o por la intensa la. bor mental, veinte años más tárde desarrollaba ma "paralisis general progresiva", cuyos primeros síntomas be hicie. ron ostensibles en Marzo del año 1920, un mes después de su matrimonio, a los 39 años de edad.

Cuatro meses ates de su ingrego al Asilo se obscrva irre. gularidadesen su conducta, ideas de grandeza y aparición de fenómenos - paralíticos. Derochador y dromómano: caminaba sin rumbo por las calles y alrededores de la ciudad, con exaltacion emocional; realizando en una ocasión una absur. da operación bancaria, habiendo falsificado groseramente un cheque por mil libras "por honorarios", firmado y eobrndo por él mismo en el banco; todo lo cual determinó a la familia a internarlo en el Asilo, ingresando el 19 de Marzo de 1920.

Al exámen se comprueba euforia, megalomanía, disartria y disgrafia, atención inestable, percepción insuticiente, incoherencia, desorientación, fabulación, pérdida de la auto-crítica, gran agitación; exageración de los reflejos, RomberG, ARGYLL-ROBERTSON. Además, WaSSRRMANN-fuertemente posi- 


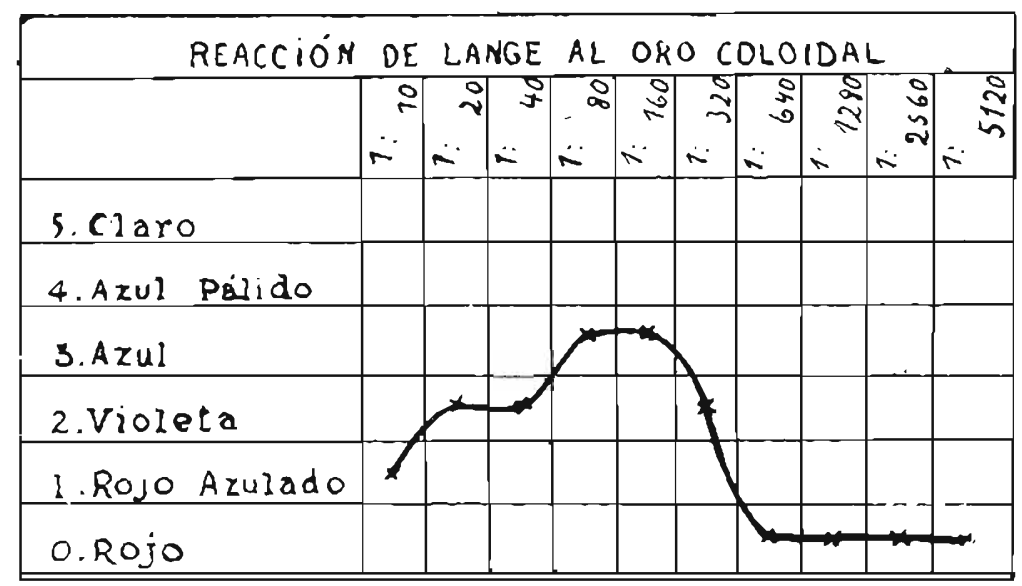

Fis.1.-Curva de sífilis cerebral

\begin{tabular}{|c|c|c|c|c|c|c|c|c|c|c|}
\hline \multicolumn{11}{|c|}{ REACCIÓN DE LANGE AL ORO COLOIDAL } \\
\hline & 운 & $\begin{array}{c}0 \\
\therefore \\
\therefore\end{array}$ & $\frac{9}{3}$ & $\begin{array}{l}0 \\
\therefore\end{array}$ & है & $\stackrel{\grave{2}}{\approx}$ & 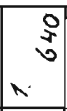 & $\pi^{2}$ & 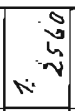 & $\frac{9}{2}$ \\
\hline 5.claro & & & & & & & & & & \\
\hline 4.Azul Pálzdo & & & & & & & & & & \\
\hline 3. A2ul & & & & & & & & & & \\
\hline 2. Violeta & ע & & & & & & & & & \\
\hline 1. Rojo Azulado & & & & & & & & & & \\
\hline U.ROjo & & & & & & & & & & $\rightarrow$ \\
\hline
\end{tabular}

Eig. 2. - Caso de Tabes.

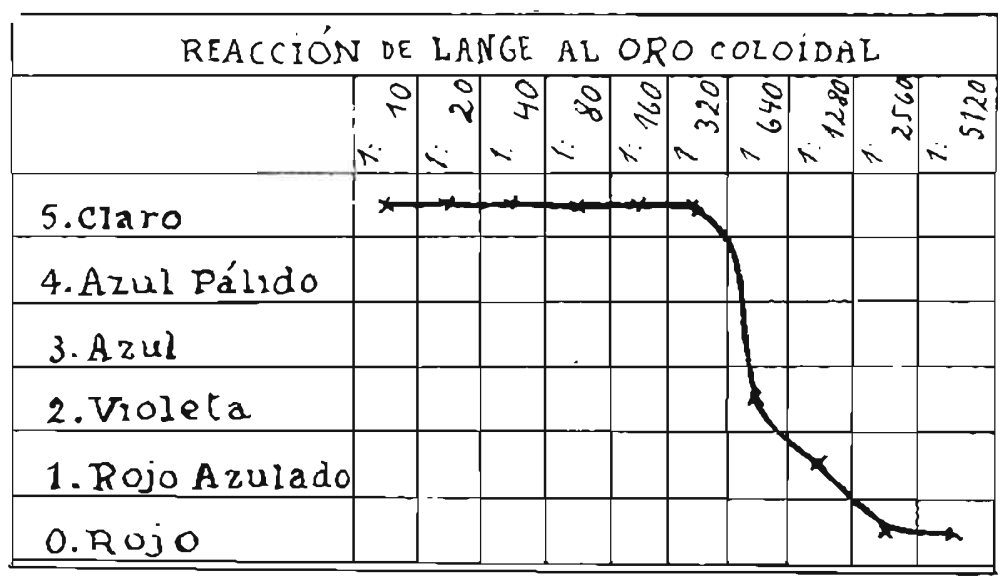

Fi8. 3.-Curva de Parálisis General. 
tiva en la sangre y líquido céfalo-raquídeo, linfocitosis y albuminosis.

Se hacen progresivamente ostensibles sus ideas de grandeza, con tendencia al delirio sistematizado. Se cree descen. diente de los Incas y de nobles españoles y poseedor de fantásticas fortunas, planeando fábulosos proyectos financieros y patrioticos. La disartria se acentra más carla día. A poco se desarrolla en diversos segmentos de su-cuerpo un temblor fibrilar y en masa, generalizando despućs, con grave incohordinacion motríz, que casi le imposibilita la marcháp presentándose al tinal de aquel año, incontinencia urinaria y fecal, y cuidas fiecuentes ul caminar, a pesar del tratamiento activamente empleado y que consiste en inyecciones de neo. salvarsán, alternadas con biyoduro de mercurio, administracion de iociuros y urotropina.

("C. A. pág. 2.")-El 24 de febrero del año siguiente (1921), previa autorización de lá familia, se le practica la primera inoculación, subcutánea, de 1 c. c. de sangre malárica, a plasmodium vivax, tomada de otro enfermo durante el acceso. Once dias después, el 7 de Marzo, presenta el primer acceso, comprobándose la presencia del parasio en la san. gre, y aun cuándo la temperátura no alcanza a $38^{\circ}$, el enter. mo experimenta profundo quebranto, quedando incapacitado hasta pata mover las piernas. Al siguiente dia lat temperatura es de $37^{\circ} 8$ con los mismos síntomas y una disartria más ácentuada. El 9 tiene $38^{\circ} 5$ con intensa postración, incontinencia urinaria y fecal y dificultad respiratoriar, alcanzando el día $10,39^{\circ} 2-$ con intensificación de los mismos sintomas, sudores copiosos, vómitos, taquicardiá e hipotensión, inyectandose por esto digitalina y aceite-alcanforado, 10 cc., dosis que es continuada en los días signientes. Al siguiente día la temperatura es de $37^{\circ} 9$ y cae a $37^{\circ}$ el dia 12 , a par. tir del cual, probablemente debido a la resistencia orgánica naturaly a las inyecciones de aceite, los accesos desaparecen. En esta ocasión nuestro enfermo ha soportado 6 accesos fe. briles, diarios, con temperaturas que han oscilado entre $37^{\circ}$ 8 y $39^{\circ} 2$, los que le han producido una intensa reacción orgánica. Se nota, poco después, una ligera mejoría en su esta. do físico y mental. En esta oportunidad el enfermo tiene una curiosa alucinación aluditiva y visual, casi una televisión, en la que dice haber visto la a parición del propio Wagner voN JaUREGG, la que al tratár de aproximarse desaparece, dando al enfermo una descripción del profesor vienés. 
El 28 de Marzo la temperatura se eleva nuevamente, com ligeromalestar, escalofríos y fiebre de $38^{\circ} 4$. Esta se repite en los días siguientes, alcanzando $37^{\circ} 3$ y $38^{\circ} 2$, observândose aumento notable en las ideas delirantes, desorientación, ligera fisminución de la irritabilidad $y$ disatria, con desaparición de la incontinencia. En Abril se repiten espontáneátmente cuatro accesos más que se presentanbastante alejados unode otro, el lía $1^{\circ}, 37^{\circ} 8$; el $5,37^{\circ} 4$; el $17,38^{\circ}$, y el $19,37^{\circ} 6$.

El11 de Mayo se inocula nuevamente con $2 \mathrm{cc}$. de sangre malárica, del caso $N^{\circ}$ (J. A.), inoculación que es repetidar el 29 del mismo mes por no haber dado resultado la anterior. Dos (lias después, el $1^{\circ}$ de Junio, presenta $37^{\circ} 5$; el $2,37^{\circ} 5$, y el $3,40^{\circ}$ con violentos escalufíos y sudor copioso; desa pareciendo después los accesos espontántamente.

Este enfermo hat soportado en total 15 accesos maláricos, casi todos con temperaturas relativamente bajas, pues. en solo tres ocasiones esta ha alcanzado $39^{\circ}$. con la pruticularidad de que, en cámbio, la muy intensa reacción orgánica producidaen el enfermo por estos débiles accesos, no ha guardado relación con la intensidad de la temperatur. El estado físico general del enfermo ha mejosado notablemente, habiendo aumentado su peso en 2 kilos. La glave incootchinación motríz ha desaparecido al extremo de que dos semanas después (icl Gltimo áccess) febril, el 16 de Junio de aquel año. (1921), podia ya caminar momalmente, correr y hasta bailar. El reflejo patelat es normal, la aniscoria hat desaparecido y el ArgYl, es insignificante; hay midriasis, no hay RomBERG. Escritura normal, vocalizacion clara, a an dumate los estados emocionates.

En la esfera mental los resultados obtenidos son án más halagadores, pues el paciente no solamente tiene una perfecta conciencia de la realidad, estando perfectamente orientado. sino que recuerda y-reconoce la naturaleza y gravedad de sus pasadoserrores y delirios. En cuanto a su carpacidad mental, a juzgar por los tests a que ha sido sometido, co. responde a lo normal, sobrepasando en velocidad en algunos de ellos, al promedio habitual.

Un nuevo exámen de L. C. R. pone en evidencia una vez más el hecho generalmente constatado por todos los investigadores, de la faltá de concordancia entre la mejoriá psíquica y los caubios serológicos, pues este arroja wua $R$. W. fuertemente positiva, linfocitosis de 8 elementos por $\mathrm{mm}$. 3. y albuminusis de $0.520 \mathrm{gr}$. p. mil. 
Después de recibir una serie completa de neosalvarsán y 21 inyecciones de biyoluro de mercurio, abandona el Asilo el 21 de Junis de 1921, sin que haya tiempo para hacer una nueva investigación en el líquido céfalo-raquídeo.

Sale clinicanente curads.

Actualmente dedicado a sus labores profesionales en las que demuestra competencia y sagacidad, revela estar en commpleta posesioude su capacidad mental, habiendose hecho car rgo Gltimamente, por disposiciśn superior, de uno de los Juz. gados de Paz de esta capilal.

Este interesante caso, por la importancia de los resultados obtenidos, y por ser el primero de los trabajos en Ameri. ca, es un éxito legitimamente halagarlor para el introductor del métedo en este Continetute.

(1) Kesámen: Namero le ineculaciones: 3 (falliria, 1).

Sangre incularlat: 6 (c). (p'n total).

Número de accesos: 15.

T:-mperaturas: $37^{\circ} 5-40^{\circ}$.

Resultado: Remisión completa.

(1) Nuta importante: En cistos tescimenes, que del trataniento piretógeno empleado hacemes de carala caso.nos referinus de modo especial a las inoculaciones con sangre malaricat cumpliendo con advertir que considerase. mos en ellos "tan solo" el namero de accesos que ham podidu ser "rigurosanente" constatados, no incluyendo le eonsiguiente las reacciones termicas ligeras ni nquellas que por circunstancias insalvables no pudieron ser comprobadas. No ha side porible conuprobar por razónanáloga, así como por haber querito insistir de preferencia en el métudo Wagner von Jaurligg. la totalidad de las series de mucleinato de sodio, con sus correspondientes reacciones térmicas, que se ha empleado complementáriamente en la mayoría de los casos, o la taberculina, usada en algunos pocos enfermos. Onitimos igualmente detallax en estus restimenes las otras sustancias antilueticas usuales que, como el biyoduro de mercurio o el neosalvarsán, hau silu emplendas de mo. do sistemático en casi todos los cásos. 
Observación $N^{\circ}$ 2.-A. L., natural de Lima, de 34 años, chsado, empleado, razáblancá, cátólico, de condición social y económica mediána, instrucción comercial completa, ingresa al Asilo a solicitud de la familia, por primera vez el 26 de octubre de 1920. Padre carliópata. El paciente ha te. nido seis hijos, el máyor de 14 y la menor de 9 años. La mujer, después del watrimonio, sufie de jacluecas. Ambiente familiar bueno. A la edad de 15 años el enfermo sufre un intenso traumatismo psíquico con motivo de la muerte del padre, y a ello refieren la enfermedad que había de estallar tantos años después. Refieren que ha tenido fiebres, pero no precisan su naturaleza, indicando solamente que le ocasionaban ataques.

Al ingresar al Asilo, está tránquilo y dócil. Tiene disartria y temblor en las extremidades. Esta delirante a conteniclo megalómano. Hay desorientarión endo y alópsiquica evidentes. Sospechándose de un proceso de neurosifilis, se practica una puncion lumbar; la $R$. W., resultá fuertemente positiva, con lijera hiperalbuminosis y linfocitosis. El 3 de novienbre es trasladado al servicio.

Esta agitado y delirate, verborreico, incoherente. Emite sus ideas en voz alta, a gritos, tomándose a veces agresi. vo. Su delirio de grandezas es el rasgo más sáltante que do. mina durante meses el cuadro clínico: “jYo soy General, Presidente, Rey, Dios; soy el Parre Eterno, yo soy el Hijo de Dios!..... Tengo millones de casas, millones de millones de hacienlas, millones de mujeres, nillones!..... Pum, pum, pum..... lo maté ya! Todavía..... mil quinientos balazos... Asesino, no lo maten, yo lo pertono. Criminales! Mc quieren matar, sí el médico, todo el mundo..... Muere mucha gente; mis hijos, sí, que vengan ....Todos son ladrones quieren robat mis expedientes; yo soy un perro, yo no tengo la culpa. sí..... Sifilíticos, sáquenme de aquí.....!n A través del delirio se manifiestan además idéas de persecución, con tendenciá a la sistematización.

Formulado el diaguóstico lle "parálisis general progresiva", después de hechas las investignciones indispensables y en vista deque su estado no sufie modificación tavorable á pesar de los cuidados y del tratániento general a que está sometido, el 24 de febrero del año siguiente, 1921 , se le prac. tica la primera inoculación con lec. de sangre malárica a pl asmodium vivax, viáa subcutánea, después de habérsele uesto una serie de 10 ampolletas de cnesol. Contináa nien- 
tras tanto en su mismo delirio, incoherente, agitado, con constantes ideas de persecución. Hay rigidez pupiar y mio. sis. Gatismo urinario noctumo.

Del 28 de febrero al 4 de marzo tiene ligeras alzas de temperatura en las mañanas, que oscilan entre $37^{\circ}$ y $37^{\circ} 5$; presentandose el dia 10 la primera ala de importancia. llegando hasta $38^{\circ} 4$, que alcanza a $39^{\circ} 3$ al siguiente dia; se mantiene en cerca de $38^{\circ}$ el día 12 , para subir el 14 , después de un dia de apirexia, hasta los $40^{\circ}$. Nueva apirexiat el 15. para alcanzar el $16,40^{\circ} 2$. Lars ideas delitantes se intensifi. candurante los accesos. El estado genemal es bueno. Parece estat aléxico, afecto de ceguera verbal, pues no puede ex. presaren voz alta lo que vé escrito. El 18 nueva alza de temperatura, $38^{\circ} 9$. El entermo en la mesa, selecciona sus alimentos, hecho que antes nunca habia realizado, pues comía atropelladamente lo que le poniandelante. Continua el gatismo urinario. Los accesos se repitell el 20,22 23 , y el 25 , con temperaturas que oscilan entre $38^{\circ} 6$ × $39^{\circ} 3$. Debido al estado de a gotarmiento físico del enfermo, se le aplican inyecciones de aceite alcanforado diariamente. La anemia es considerable: $1,965.000$ hematies y 15.000 leucocitos, habiendo 4 hematies nucléados por cala 100 leucocitos. Los accesos no han vuelto a repetirse; habiendo tenido en total 9 accesos fiancos con altas temperaturas.

Continara delirante, megalómano, aunque menos verborreico, habiendo desaparecido el gatiemo urinario. Está más calmado y sus soliloquios los hace en yoz tranquila babiendo abandonado la forma ruidosa y enfatica de antes. La marchá es dificultosa, siendo necesario sostenerle a veces para que no caiga. El 23 de abril 1921 , tiene una alza espontánea de temperatura, de $38^{\circ} 4$, y otra el 25 , de $39^{\circ} 6$. Sigue en su delirio; incoherente, tranquilo. No reconoce a su madie y a suesposa en las dos ocasiones que van a visitarlo.

El 11 de mayo se le ha practicado una segunda inoculación de sangre malárica, 2 cc. vía subcutánea. Como hasta el día 29 no se presenta niuguna reacción, es iooculado por tercera vez en la misma forma, presentándose al siguiente día 30 un acceso malárico típico como intensa reacción fe. bril que alcanza a $40^{\circ} 2$. Como no se puede suponer un período de incubación de solo 24 boras, es indudable que la tercera inoculación actuo meramente como un elemento anaflactogénico que rompiendo el equilibrio humoral que permitía la latencia del estado malárico, produjo entonces 
el choque coloidoclásico, determinante de las diversas fases del acceso paladico. Este fenómeno, que por lo dembis se ha repetidoen muchosde los casos tratados, se produce también bajo la acción de una inyeccion de adrenalina o de nucleinato desodioauncuandoeneste fitimo (áso el tenómeno es menos aparente, debido a la reacción febril casi inmedialádque de por sí determina la sustancia mencionada.

El violento acceso del día 30 se continfa repitiendo diaramente hasta el 14 del siguiente mes de junio, todos casi con igualintensidad. Así soporta el pacience hasta 16 acce. sos maláricos, - con su cuádro clínico típico, con temperaturas que en casi todos se han mantenido por encima de $40^{\circ}$, sobrepasándolosen 9 de los 16 accesos. los que han tenido un máximum de $40^{\circ} 8$ el día 14 , y un mínimum de $37^{\circ} 8$ el día 10. Tres inyeceiones de quinina de 1 gr. cada una, cortan la serie de accesos, debidoal delicado estado del enfermo; pues se han presentado edemas. El exámen de sangre arrojá de 3.900.000 hematies y 7,100 leucocitos; la anemización há sido insignificante en proporcion a la severidad de los accesos soportados.

Su estado mental en aquella fecha continta sin modificación considerable, siempre con sus icleas de grandeza, verborreico perocalmado, disártrico y con dificultad en la marcha. Hay además, gran desorientacion alopsiquica y una forma seriat de dismnesia, pues no ha podido reconocer a su madre en una visita que esta le hace, diciendo: "Esa no es mi madre ni mi familia; quien sabe de donde hablá venido; mi familia vive en Lima y tiene otra cara.....".

En el curso de los meses de Junio y Juliose le aplica una serie de neosalvarsán y otra de 16 inyeccioncs de biyorluro de mercurio.

Descansa en Agosto, y en Setiembie se le aplica una nuevar serie de neosalvariátu. El 22 de Octubre, nueva inoculación de sanurre malárica a plasmodium vivax, forma vegetativa; perono se obtiene ninguna reaccinn. A fines de Noviembre se comienza otra serie de neosalvar rán, alternándola con biyonisude metcurio. A pesar de esto no se observa mejol'á en el estado del enfermo.

El $1^{\circ} \mathrm{de}$ Diciembre se practica otra inoculación eon $1 \mathrm{cc}$. de sangre paladica (por $5^{a}$ vez), suspencliéndole todo otio tratamiento. Ningan resultado. Nueva inoculación el día 17. Quince dias después, el 2 de Enero tiene una perucina elevación de temperatura, y al siguiente día en la noche otra que llegáa $39^{\circ}$, con gran decámiento general, náuseas, vómitos 
y sudor copioso. El día 4 (Enero, 1922), tiene $37^{\circ} 8$; apiréti. co el 5 y el 6; nuevá alza a $40^{\circ} 5$, el 7 en la mañana; $40^{\circ}$ el 9 , y $39^{\circ}$ el 11 ; ligerá reación el 12 y el 13 , y apirexia a partir del 14, espontáneamente. En total, seis áccesos típicos.

Está tranquilo, aunque siempie delirante; la marcha es lenta, pero firme. Después de nueve dias de apirexia, el 22 de Enerose presentan nuevalunente los accesos paládicos, llegando la fiebre a $39^{\circ} 8$, repitiéndose estos casi diariamente, pero alternándose los de mediana intensiclad con los de reaccion intensá, hasta el dia 5 de Fcbiero. Sufie en total 7 accesos tipicos, con tenuperaturas que casi siempre han sobrepalsado los $40^{\circ}$, a parte de tres o cuatro reacciones de menor intensi. dad. Como dato de interés, señalaremos que el día 5 de $\mathbf{F e}$. brero recibe la visita de su esposa y de sa madre, a quienes esta vez ha reconocido, especialmente a está áltima por primera vez; respondiéndoles a las preguntas que les dirigían. Los accesos desaparecon espontáneamente como vinieron.

Conligeras alternativas en sa estado mental, transcuren los meses de Marzo y Abril, en los que recibe otra serie de neosalvársán.

El 17 de Abril se comienza otra serie de inyecciones de tuberculina subeutáneas, comenzando con 5 milígramos, y aumentandola dosis de 5 en 5 miligramos cada cuatro días, hasta llegar a $1 \mathrm{gr}$. por día. El 29 se interrumpe este tiata. miento para inocular $2 \mathrm{cc}$. de sangre malarica a este enfermo, inoculación que por 110 haber dado resultado. es repelida el 13 de Junio, presentándose el primer acceso tres días después, el 16, con escalofirios y fiebre de $39^{\circ}$; sufie asi hasta 6 aece. sosque se repiten diariamente entre $38^{\circ}$ y $39^{\circ}$, y desaparecen sin medicación al guna.

Sin modificación manifiesta de su estado mental. trascu. rren tres meses más: tranquilo, sin delirar espontáneamente, nunca ruitoso, bien adaptada su conducta at la vida de Asilo, después de haber sido el enfermo más dilícil del pabellón, se ha tomado en uno de los más tranquilos. Con una constitución predispuesta, y una infección luética cuyo orígen se remonta a 1914 , este enfermo que ingresó en grave estado en 1920, después de haber soportado en el servicio 49 accesos maláricos de gran réacción térmica y escasa repercusion en su estado general, experimenta en esa épocá la remision de algunos de sus más graves síntomas, habiendo desáparecido ta intensa y permanente agitación psicomotriz, la indocili. 
dad, el gatismo, la verborrea y la incapacidad de ejecutar movimientos coordinados.

Trasladado por razones econbmicas y por indicación de la familia a otro servicio el día 24 de Julio de 1922 , permanece actúllmente allí, sometido a un tratamiento reconstituyente y antiluético. El 4 de Junio de 1923 se le inoculó en aquel servicio con 2 ce. de sangre malárica, vía endovenosa, obteniéndose despućs de uná incubación de 10 días, nná considerable serie de accesos, casi todos con elevada reación fe. bril, 12 en total, con temperaturas que oscilaron entre $37^{\circ} 4$ y $40^{\circ}$, de curso irregular, los que hubo necesidad de interrumpir mediante la acción de la quinisa, el 6 de Julio, debino al estado de agotamiento físico del enfermo.

Tiene episódicamente períodos de ágitación psico-notríz de muy lijera intensidad, a las que siguen estados de depresión y untisuo. Se le ha inyectado en aquel servicio duran. te estos dos fltimos años algunas series de nucleinato de sodio, alternadas con neo-salvarsán.

Actualmente está ind iferente, introvertido, desorientado crono y alopsiquicamente. Lengaaje musitante. Automatismo verborreico esporadico. Aniscoria, Argill-Robertson. Deambuación normal, no hay Romberg, habiendo desaparecipo la disartria y la incoodinación motriz.

Tales el estado atctual del eufermo, que si no ha evolucionado muy fuvolablemente en la esfera mental principalmente por intervenir factores de orden constitucional, el tratamiento malárico ha logrado en cambio hacer desa parecer los graves trastoruos paralíticos que este enfermo presentaba a su ingreso, los mismos que permanecieron sin modificación bajo la acción de la medicación antiluética, como el neosalvarsán por el que el enfermo llegó a mostrar graves síntomas de intolerancia.

Resúmen: Numero de inoculacioues: 8 (fallidas, 3).

Sangre inoculada: $14 \mathrm{cc}$. (en total).

Número de accesos: 61 (más 6 a 8 ligeros).

Temperaturas: $38^{\circ}-40^{\circ} 8$.

Resultado: Remision incompleta.

Observación $N^{9}$ 3.-J. A., natural de Tarma, de 39 años de edad (en la actualidad), mestizo, carpintero, ingresa al Asilo a solicitud de su familia, el 14 de Abril de 1921. Debe- 
mos advertir que este enfermo, víctima de una psicosis distinta a la P. G. de la que de preferencia nos hemos ocupado, se benefició de la acción piretógena y biologica del plasmodium vivax por haber contraido accidentalmente el palndismo, poco antes de su ingresu al Asilo, en el que no existía entonces un solo cáso de malaria; siendo el que suministró la sangre para la inoculación de los primeros casos que entre nosotros tratara con éxito el Dr. Honorio F. Delgado. Lo consignamosen el presente trabajo porque en su curación no intervino otro agente que el paludismo acciclentalmente contraido.

Se desconoce antecedentes de la enfermedad, así como he. reditarios y personales.

A su ingreso se constata: estado de gran depresión, desorientado crono y alopsíquicamente, dispronexia, bradilalia, dismnesia. Indiferencia absoluta por cuanto le rodea. Introversión episódica. Percepción lenta, poco níticla. Disbulia. Ideación retardada. La R. W. del líquido céfalo-ráquídeo, que primero dió resultado incierto, después de algunas inyeciones de nucleinato, resulto débilmente positivá y con una manifiestá linfocitosis (linfocitos, $20 \mathrm{p}$. $\mathrm{mm}$. 3; albuminosis, 0.420 p. mil. Abril, 30 ). Hay gatismo urinario.

Se formula, en vista de lo que antecede, el "diagnóstico" de "demencia precóz"; comenzándole por aplicarle una serie de inyecciones de nucleinato de sodio a dosis creciente. Además, pociones de urotropina, a continuación de un enérgico purgante salino.

El día $1^{\circ}$ de Mayo de 1921 en la tarde, presenta expontáneanente un acceso pálúdico con fuerte reaccion febril que llega a $40^{\circ}$; pero como estáán en periodo de observación, se le aplica una inyección de quinina, trátamiento químico que es continuado durante algmos días. A pesár de esto, el 3 se presenta un nuevo acceso; el 4 es trasladado al survicio de pensionistás, y en los días 7 y 9 , tiene dos accesos más, sumando $z$ en total, todos de $40^{\circ}$. El día 11 , se le extrae sangre para inocular a otros enfermos (previa comprobacion microscópica del plasmodium vivax), afectos de parálisis general progresiva. La numeración globular arrojá las siguien. tes cifras: hematíes, 4.100 .000 ; leucocitos, 8,200 . Se observa, comoda to interesante, vál rias veces comprobado que los accesos se suspenden a raiz de la extracción de sangre. El estado mental del enfermo ha experimentado sorprendente mejoría; está orientado crono y alopsíquicamente, coherence ylacido. 
E1 23 y el 25 de Mayo tiene otros dos accesos con $39^{\circ} \mathrm{g}$ y $39^{\circ}$ de temperatura. Se extrae sangre pera inocnlar a otros enfermos, y los accesos desaparlecen nuevamente. Hay cierta dificultad en la marcha. No hay Romberg. Manifiesta, además, experimentar cierto grado de adormecimiento en la mitad izquierda del cuerpo. El 10 de Junio presenta otro acceso aislado, con $39^{\circ} 8$ de temperatura.

En el mes de Julio, el estado físico y mental del enfermo es muy satisfactorio. Está lúcido, tranquilo, contento, bien orientado, perfectamente consciente. Se alimenta con apetito y tiene sueño tranquilo. Los trastornos de la marcha han desáparecido, al punto de poder dedicarse todas las mañanas a carreras y otros ejercicios físicos análogos e igualmente demostrativos de su eficiencia en la equilibración y en los movimientos coordinados.

En atención a la perfecta normalidad de su estádo físico y mentaly de su absoluta capacidad para el trabajo, es dado de alta el 17 de Agosto de 1921, "clínical" y "serológicamen. te curado".

Conviene advertirque un fltimo exámen de sangre y lí. quido céfato-ráquídeo practicado con fechá 2 de Julio, dió el siguiente resultado: R. W. "negativa en ambos": linfocitosis, 9 p. mm. 3 (en vez de 20 q' tuvo en Abril, antes del paludismo). y albuminosis, 0.220 (en vez de 0.420 p. mil.).

Eseste pues un caso de "demencia precóz", que sale clínica y serologicamente curado en el corto espacio de 4 meses debido a la exclusiva acción de 5 accesos palfadicos ocasionalmente contrálios, lo que evito la indicacion de una inoculacionartificiál según la técnica de Wagner-Ja UREGG. Y está curaciónque ha interesado por ignal las trés esferas. física mental y serológica, se ha realizado sin recurrir a ningan compuesto ársenical.

Resámen: 1 inoculacion accidental;

7 áccesos.

Temperaturas, $38^{\circ} 8-40^{\circ}$.

Resultado: Curación completa.

Observación $N^{\circ}$ 4.-L. G., de 41 años, blanco, casado, comerciante de holgádát situación, ingresá al Asilo en febrero de 1921. 
Desde principios de 1920, comienza a experimentar cambios de carácter y a observar una conducta extravigante, a tal extremo que la familia comprendiendo la naturaleza pa. tolbgica de aquellos actos solicita la intervencion de un especialista; evidenciándose pupilas perezosas a la luz. marcada ataxia estática y quinetica, disartia, temblor en las manos e ideas de grandeza. El exámen de líquido céfalo raquídeo demuertra una $R$. W. fuertemente positiva, hiperlinfositosis e hiperalbuminosis. Antes desu ingreso fué tratado con mercurio por corto tiempo, y abandons después todo tratamiento antiluético, hace crisis el estado mental del enfermo en febrero del año siguiente 1921 , realizando ataques agresivos tanto en su casa como en lá cálle, y sufriendo a poso un ataque a poplético que le dejó en estado de coma, cou pulso arrítmico y $38^{\circ}$ de temperatura. Al salir del estado comatoso su condición física era deplorable, por lás lesiones que él mismo en sus (lelirios se infirió con equímosis, escoriaciones y escaras. Presentaba aclemás tembior en la mitad derecha del cuerpo, alucinaciones visuales y auditivas de carácter terrorifico que culminan en estado de gran agitación psico-motriz: disartria y a reces anartria, incontinencia fecal y urinaria, incapacidad para mantenerse en pie, de. sigualdad pupilar y disfagia. En vista de esto, se hace el diagnóstíco de parálisis general progresiva.

El estado del paciente contináa estacionario aún degpués de un tratamiento antisifítico intensivo.

En mayo 11 , se le inoculan $2 \mathrm{cc}$. de sangre malárica, con autorización de la familía, a la que se le previene de la deses. perada coulición del enfermo, agravada por las escaras que presenta en las regiones sália y glúteá. El 21 del mismo mes, derqués de diez días de incubación. se presentá el primer acceso, con temperatura noderada, $37^{\circ} 6$; teniendo en los dos días siguientes $38^{\prime \prime}$ y $37^{\circ} 6$, sin reacción orgánicia. Dós dias de apirexia y nuevar rércción el 26 , con $40^{\circ} 2$ y violentos escalofríos. A partir de aquel día y hasta el 4 de junio se presentaron diarianente las elevaciones térmicas, casi todas pasando de $39^{\circ}$ y algunas alcanzando $40^{\circ}$. Estos accesos, que en total produjerón 22 reacciones térmicas, cesaron espontáneamente.

El estado mental alel sujeto mejotó notablemente desde los primeros accesos, desapareciendo la gran agitación psico motriz, así como las ickeas de persecución y las crisis de agresividad. 
En vista de la profunda anemia, se instituyó un tratamiento quínico y arsenical, administrándosele diversos tonicos y reconstituyentes para luchar con la intensa postración y debilitamiento orgánico del paciente. agravada por haberse infectado una antigua escara glútea.

A pesar de ello, el estado general continuó empeorando, no obstante la grán mejoría obtenicla bajo la acción del paludismo en la eslera mentál, y el enfermo fallecio en estado de gran postración el día 12 de junio de 1921 .

Es de notar que en este enfermo se produjo una notable mejoría en sus síntomas mentales a pesar de ser un P. G. con uná escara geáne antigua.

Por desgracia, lo avanzado y severo del caso y el estado de gran desnutrición en que se haliaba el enfermo a su ingreso al Asilo y del cual no se le pudo sacar, impidieron obtener en la esfera fisica el mismo brillante resultado que en tan corto tiempose obtuvo, con lá inoculación malárica en la esferat mental.

Resumen: Número de inoculaciones: 1 .

Sangre inoculada: $2 \mathrm{cc}$.

Número de accesos: 22.

Temperaturas: $37^{\circ} 6-40^{\circ}$.

Resultado: Muerte (Caso muy avanzado).

Observación $N^{9}$ 5.-E. V. C., de 27 ã̃os de edad, mestizo, soltero, de oficio conductor de tranvía, de carácter afectuoso e inteligencia despierta. Contrae un chancro en agosto de 1918, que fue curádo con tópicos locales sin instituir tratamiento específico. En noviembre del año siguiente sufre un desvanecimiento cayendo al suelo, teniendo que ser puesto en cama por la imposibilidad de mantenerse en pie. A partir de entonces experimenta cambios de carácter, volviendose irritable y violento, al mismo tiempo que pierde progresivamente su capacidad para el trabajo, por lo que lo despiden sus jefes. A fectado por esto, se dá a la bebida. A poco le sobrevienen temblores fibrilares en las manose inestabilidad ell la marcha, disartria y disgrafia marcadas. Se cree rico y poseedor de varias fincas. El delirio de grandeza quedá establecido.

Ingresa al Asilo el 18 de enero de 1921, en estado tran- 
quilo, indiferente, desorientado, manifestando un estado de infantilismo mental, egotismo, euforia, fabulacion, ideas de grandeza, hiperminia, agripnia. amnesia, disartria, disgrafia inseguridad en la marcha y temblor fibrilar en las extremidades, Argyl-Robertson, R. W. fuertemente positiva en el líquido céfalo-raquídeo y negativa en lá sangre.

En rista de esto, se formula el diagnóstico de parálisis general progresiva.

Se sigue un activo tratamiento con enesol, neosalvarsán y ioduros. Mejora esto en algo su estado mental, pero persistiendo en toda su intensidad los sintomas palalíticos.

Este era el estado del enfermo en mayo de acfuel año 1921, El 29 se le inocula con $2 \mathrm{cc}$. (le sangre malárica a plas modium vivax, subcutáneamente, apareciendo el primer acceso 18 días después, el 16 de junio, con $39^{\circ} 5$. Estos accesos se repiten diariamente hasta el dia 28 que cesan debido a una inyección de neosalvarsán. Fueron trece en total, oscilando las temperaturas entre $38^{\circ}$ y $41^{\circ}$, en cuatio de los cuales la temperátura pasó de los $40^{\circ}$, manteniéndosi en los demás en un promedio de $39^{\circ}$.

El estado mental experimento mejoría desde los primeros accesos, desapareciendo la disartriá en los áltimos, juntamente con álgunos otros signos neurológicos, pudiendo decirse que poco después de concluídos estos accesos, el estádo del entermo era de curación casi completá, con sólo persistencia (1) Argyll, anisocoria, hiperreflectividad en los miembros, pero con seguridad en lat marcha. Percepción y juicio, nomales como lo demuestran los diversos tests a que fué somctido, Fersistía algún defecto en la elaboración mental y eu lá cápaciulad crítica.

A parte de estos ligeros defectos, ha recobrado su capacidacl para el trabajo, tanto físico como mental, a pesar de mantenerse la $R$. W. fuertemente positivá en el líquido céfalo raquídeo y presentarse debilmente en la sangre, lo que demuestra una vez más que estas tienen tan sólo un valor diaguóstico, o por lo menos que su persistencia después del tratamientoes perfectamentecompatible con la desaparición de las manifestaciones físicas y mentales de la enfermedad.

Después de tratarlo intensivamente con mercurio y neo. salvarsán, es dado de alta el 5 de setiembre de 1921, clínica: menre curado.

El 29 de octubre de ese año se le investig6 las condicio. nes del líquido céfalo-raquídeo, con el siguiente resultado- 
R. W, negativa; albuminas, $0.200 \mathrm{gr}$. por litro; linfocitos, 3 p. m. 3. Sangre: R. W. negativa.

Se ha destinado como vigilante en la Penitenciaría, donde, además de su trabajo cotirliano, tiene que pasar tres noches por semana en vela. A pesar de esto, está muy bien, con retorno completo a la normalidad. Hace más de tres año: y medio rue no se cura en ninguna forma.

Un reciente exámen de liquiclo céfalo raquídeo, practicádo a este enfermo por el Dr. Guillermo A LMrivars, bacterib. logo del Asilo, a solicitud (lel Jefe del Pensionado de Varones Dr. Honorio F. Disiga Do, con fucha 11 de agosto de 1925 , dá el siguiente resultado: Tensión intraraquílea: normal; Aspecto y color: normales; Reacción de Wassernam: Negativa; Allúminas totales: 0.250 r. mil; Globulinas: nomal; Linfocitos por mm. 3: 4 (Fuchs Rosenthal).

Esto nos demuestran que los electos del tratamiento piroterapico en la P. G. progresiva se dija sentir, a veces, no solamente en la vactua a la normalidal del sujeto en las esferas física y mental, sino arnen la scrologica. Siblo que esté último hecho, tarrlio cuando se revlizir-y esto e’s más fie-

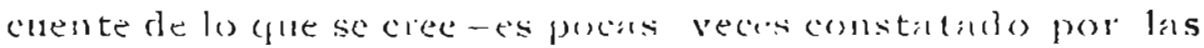

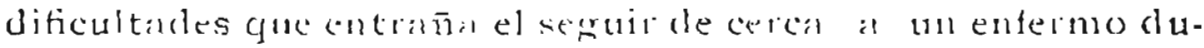
raute anos, cuatulo ha abondonado el is silo.

Resumen: Nómero de inoculaciones: 1 .

Sangre jucculata: $20 \mathrm{c}$.

Núnero de accesss: 13.

Temperaturas: $38^{\circ}-41^{\circ}$.

Resultado: Remisión completa.

Observación No. 6.-L. G., de 60 años de edad, natural de Hungría, de ocupación minero, ingresal al A silo el 15 de marzo de 1921 . Casido, con hijos.

Ingresa al servicio el 11 deabril de 1921, en estado de gran agitación psico-motora. Clinoterapia prolongada. Alucinaciones e ilusionts visuales $y$ auditivas. Impulsos agresivos y dromoníacos. Ideas delirantes megalomaniacas. Atención inestable. Juicios aberrantes. Fabulacion multiforme. Desorientacion completa. Aversión a la tamilia. Eufórico. Anisocoria moderada y Argyll incompleto. Esbozo de Romberg. Temblor fibrilar en manos g lergua. 
Disartria discreta, Disgrafia episodica. Gran agitación y erotismo exagerado los primeros días, depresion y fase neurasténica después. Negativismo y recházo de alimentosLinfocitosis y R. W. tuertemente positiva en el líquido cétalo raquídeo. "Diágnóstico: P. G. progresiva."

Estádo ulterior: melancólico, tranquilo, hermético. De lusiones de persecución.

Se le aplica una serie completa de neosalvarsán, y se le administra nrotropinat. Continá agitado, delirante, con ideas de persecución. Cree que tratan de envenenarle e insulta a todos tratándolos de ladiones. El examen de líquido ráquíleo prácticado a fines de junio dió el resultado siguiente: R. W. fuertemente positiva; linfocitos, $18 \mathrm{p.} \mathrm{mm}$. cúbico, úrea, 0.20; glucosa, 1.084 .

El 22 de octubse se le inocula 1 ec. de sangre malárica vía subcutánéa, suspendiéndose, como siempre se háce, toda medicación, a fin de no enmascarar los resultados. No se presentá en más de un mes ninguna reaccion, por lo cque se le aplica una segunda serie de neosalvársán. Fin diciembre, segunda inoculación de más de 1 ce. de salagre malárica, sin que tampocose obtengat la menor reacioin.

En enero de 1922, el 28, en vista de la resistencia orgánica a las dos inoculaciones anteriotes, se le practica una tercera con 2 cc. a plasm. vivax subcutáneamente. Diccisiete dias después, el 14 de tebrero, se presenta el primer acceso, con relajacion muscular, afasia, fiebre de $40^{\circ} 2$. Lal afasia desaparece al siguiente dír. El $15 \mathrm{y}$ el 16 . nuevos accesos típicos con reacciones febriles 1 e $39^{\circ} 6$ y $37^{\circ} \mathrm{S}$ respectivamente. Después la fiebre desaparece espontáneamente.

El 18 de abril, se le inyecta subcutáneamente 5 miligramos de tuberculina (tubetculina antigua) disuelta en suero Hayem. El 20 , se le inyectá 10 miliglamos ( 5 cc. de la solución), el 24.15 milígramos, y el 28,20 mgr. En ninguna de estas inoculaciones de tuberculina se observa tampoco la menor reacción febril. Esta falta de poder reaccional unte diversos estínulos lebe estar ligada a alginn factor constitucional cuya razón íntima sería interesante precisar.

El 29 de abril, cuarta inoculación de sangre maláricá. 2 cc. subcutaneamente, sin resultado. El 13 de máyo, quin. ta inoculación en igual proporcion, igualmente sinque se obtenga reacción general perceptible. El mes siguiente la conducta del enfermo se armoniza mejor con la vida comín, es- 
tá más tranquilo. Las ideas delirantes no se manifiestan. Está coherente y bien orientado.

Es dado de alta, muy aliviado, el 5 de julio de aquel año (1922).

Este enfermo falleció, meses después, ya en su domicilio, de una enfermedad intercurrente (disentería) cuando estaba casi restablecido de sus trastornos paráliticos.

Resumen: Núnero de inoculaciones: 5.

Sangre inoculada: $8 \mathrm{cc}$. (en totál).

Número de accesos: 3.

Temperatura: $37^{\circ} 8-40^{\circ} 2$.

Tuberculina: 4 inyecciones, sin reacción tebril.

Resultado: muy aliviado (al sálir del Asilo).

Observación No. 7.-M. M. F., de 54 años de edad, na. tural de Arequipa, mestizo, agricultor, ingresa al A silo el 12 de agosto de 1921, tranquilo pero desorientado totalmente, en completo estado confusional. No se ha podido comprobar la fecha en que comenzó la enfermedad. La infección luética de que es portador, tuvo su origen hace muchos años. Está abúlico, indilerente it cuanto le rodea, incoherente. Se le ha practicado, antes de su ingreso, una $\mathrm{R}$. W. en el líquido céfalo.raquíleo, con resultado positivo. Se alimenta bien y cumple con sus necesidades orgánicas. El 3 de setiembie es trasladarlo al servicio.

Se comienza por una serie de neosalvarsán, previo un examende srina que 110 arroja nada anormal. Presenta sintomas de sordera verbal.

El 22 de octubre, después de formulado al "diagnostico de parálisis general progresiva", en virtud del examen psicofísico (fenomenos paralíticos, disartria discreta, desigualdad pupilar, etc.), se le inoeula con 1 ce. de sangre malárica, a plasm. vivax, vía subcutanea. Se suspende, como es cos. tumbre, todo otrotratamiento. No bay delirio de grandezas, pero desconoce a su familia, distráldo y descuidado en el vestir. Once días después, el 2 de noviembre se presenta el primer acceso malárico, con escalofíos, $37^{\circ} 8$ de temperatura y muy escaso sudor. A partir de aquel dia, se suceden diariamente los accesos hasta el dia 7 , con temperaturas de $37^{\circ} 8$, y a partir de entonces, después de unos días de ligeras 
reacciónes febriles, éstäis desapareceir espontanneamente, después de un total de 5 accesośs, con reaciónes febriles mediocres, casi sin escalofríos ni sudor.

Como su estado mentalcontináa estacionario: delirante. impulsivo, con gatismo nasal y urinario constantes, el $1^{\circ} \mathrm{de}$ diciembre se le inocula con 1 cc. de sangre malarica, subcutaneamente. La perseveración de respirar fuerte y ruidosamente ha disminuído, asi como la de rascarse hasta sacarse sungre. Con este motivo se le han formado varios pequeñós ábcesos en diversas partes del cuerpo. El 15 se repitela inio. culación, y dieciseis días después, el $1^{\circ}$ de eneio de 1922, se presenta el primer acceso paladico con malestar, escalofrios Gebre de $38^{\circ}$ y sudor abundante. Al siguiente día, $37^{\circ} 6$; después, apirexia.

Está indiferente a todo, tranquilo, ligeramente desorientado, delirando constantemente con caballos. No reconoce a ning an miembro de su tumilia.

En febrero y marzo se le aplica una serie completa de neosalvarsán. A pesar de ello continúa con uná forma espereotipada de delirio, en torno de "sus caballos blancos que por millones le han robado esos cholos ladrones". El gatismo ha desapaeceido. Se alimenta bien, tiene sueño tranquilo.

El 17 de abril se comienza una serie de tuberculina, empezando con 5 miligramos, aumentando cada cuatro días una cantidad igual, siendo la segunda dosis de 10 milígramos, la tercera de 15, y así sucesivamente hasta llegar a 1 gr. por inyección, casi sin reacción tebril.

El 29 de abril, interrumpiendo momentáneamente el tratamiento por la tuberculina se le inncula por cuarta vez, 2 cc. de sangre malarica.

La inoculación no da resultado; se hace una nueva el 13 de mayo, con sangre, a plasmodium vivax, extraída de otro P. G. en tratamiento palfico.

El día 14 es víctima de cuatro "ataques epileptiformes" de regular intensidad, con grito agudo inicial, contracturas, sacudidas fuertes de las extremidades, mordedura de la len. gua y respiración profunda. Después se calma.

Contintia delirante, siempre con el mismo tema de los caballos robados, en estado de semi-excitacion psico-motriz, violentándose con frecnencia.

En vista de que probablemente por estar agotado el poder reaccional del enfermo, las inoculaciones últimas de san- 
gre malárica no han dado resultado se comienza a inyectar-le a partir del $1^{\circ}$ de junio una serie de nucleinato de sodio progresivamente creciente de cincuenta en cincuenta centígramos, hasta llegar a $4 \mathrm{gr}$. por inyección. Se le practican 7 inyecciones, "sólo tres de lás cuales producen reacción febril, pero muy débil a pesar de las fuertes dosis inyectadas".

En vista de esta casi falta de racción por parte del enfermo, se comprende que no queda náda que hacer. El delirio y la agitacion continán, y el debilitamiento físico del enfer. mo va aumentando favorecido por la serie de abcesos que el mismo se ha formado por la manía de rascarse hasta producirse heridas, que el mismo se infecta, a pesar de todos los cuidados.

A causa de su extrema debilidád, se le inyectan diariamente 10 cc. de aceite alcanforado. La debilidad continga a pesar de esto, no puede ingerir alimentos solidos; incapa. citado para tenerse en pié; duerme muy poco, y apeuas si puede articular palabrá.

En estas condiciones le sorprende la muerte en la madrugada del 5 de julio (1922).

Resumen: NGmero de inoculaciones: 4 (tallidas, 2).

Sangre inoculada: 600 .

NGmero de accesos: 11.

Temperaturas: $37^{\circ}-38^{\circ}$.

Resultado: Muerte (cáso muy avanzado).

Observación $N^{\circ}$ 8.-C. C. A., natural de Cajamarca, de 31 años, raza blanca, casado, dentista, experimenta desde el mes de setiembre del año 1921 trastornos nervioso, dentro de una vida muy activa y llena de sufrimientos de diver. sa indole. Chancro en 1910. Meses después, placas mucosas. en la garganta y alopecía. No hay neuropatía en sus ante. cesores. En 1920 es someticlo a un tratamiento mixto de salvarsán y mercurio. La primera inyección de salvarsân, que fue de $0.60 \mathrm{gr}$. (!), le produjo un shock violentísimo que casi origina un desenlace fatal. Ha recibido además hasta 14 tubos de aceite gris, lo que confirma la opinion de varios

(1) El poder de este enfermo fú caso nulo, pues además del tratamien. to malarico, recibió, como queda indicado, "veinte inyecciones de tuberculina" $y$ "giete de nucleínato, casi todas sin producir ninguna reacción febril-- 
investigadores acerca de la ninguna eficacia de los compuestos mercuriales para prevenir las complicaciones nerviosas de la sifilis. A partir de febrero de 1921, insomnios fiecuentes, astenia profunda, adormecimiento de brazos y piernas, sensacióf de pesantez cn el cerebro, perdida de la memoria, dolores lancinantes, sensibilidad exquisita en el pulpejo de los dedos, escozor en las vías digestivas superiores y sensación de cuerpo extraño ell el exófago. Impotenciá e indiferencia génesis, Ligero esbozo del signo de Romberg. Tremores en el maxilar interior.

Todos estos signos son aureciados en el examen practicado a su ingreso al Asilo, el 11 de octubre de 1921; siendo trasladado al servicio el siguiente día. Abolicion de algunos reflejos, tales como anbos r. cubitales, el r. radial izquierdo maceterino, cremasteriano $v$ abdominal. Las pupilas no reaccionán a la luz ni a la acomodación, están inertes, desiguales; hay inversión del reflejo óculo-cardiaco (88 antes 92 despues), no hay Kernig. Ligera agrafia: no bay Jisartria. Amnesias fugaces. Ideas de suicidio. Ha cambiado de cáácter y a ratos está impulsivo. R. W. positiva en el líquido céfalo-raquídeo y támbién en la sangre.

En vistá de todos estos datos, se furmula el diagnóstico de síflis cerebral.

Se le somete a un tratamiento iodurado y mercurial; inyecciones de enesol. Estas determinan insalivación exageradísima.

El 22 de octubre de $\mathbf{1 9 2 1}$ se le inocula con $1 \mathrm{cc}$. de sangre malárica, vía subcutánea; pero tan solo se obtiene reacciones casi insignificantes.

En el curso del mes de noviembre se le aplica una serie de neosalvarsán que es bien tolerada por el enfermo.

El $1^{\circ}$ de diciembre, nueva inoculación de 1cc. de sangre malárica, a plasmodium vivax, también sin resultado.

El día 18, tercera inoculación, que es seguida, después de 11 días de incubación, de un primer acceso malárico con temperatura de 38.5 y sudor copioso. Estos accesos se re. piten diariamente, "cási todos de gran intensidad", con temperaturas que oscilan entre $38^{\circ} \mathrm{y} 41^{\circ} \mathrm{C}$. Llega a soportar hasta 16 accesos, eu 13 de los cuales la temperatura alcanza o sobrepasa a los $40^{\circ} \mathrm{C}$. El f́ltimo acceso tiene lugar el día 13 de enero 1922, en la tarde. El día anterior se le ha in. yectado 6cc. de aceíte alcanforado para combropar si este tiene poder para detener los accesos. Como en la tarde de 
ese mismo día, a pesar de la inyección de aceite, se renliza di alza cotidiana de temperatura, al siguiente día temprano se le aplica una inyección de quinotormo, seguida a poco de otra de neosalvarsán de a 0.30 gr., con el objeto de comprobar si esta fultima neutraliza la acción de la quinina, lo que parece que en efecto ocurre, pues el acceso se presenta con la intensidad de siempre esa misma tarde $41^{\circ} \mathrm{C}$. Una nueva inyección de quinoformo, aplicada el día 14, corta definitivamente esta larga serie re accesos.

El enfermo, que ha quedado bastante debilitado debido a la inoculación del paludismo, contin ra de inmediato con sus mismos síntomas, en especial sensacion de pesadéz en la cabeza y adormeciniento en ambos brazos. Se le áplica, además, una serie de neosalvarsán.

Hacia fines de Febrero el enferno comienza a experimentar los benefrciosos efectos de la inoculación malárica, pues a parte del mejoramiento progresivo de su estado general y mental, van desapareciendo rápidanente los fenomenos paralíticos, normalizándose el estado de los reflejos y de la sensibilidad.

El 16 del mismo mes declara en una comunicacion correctamente escrita y dirigida nl Jefe del servicio, Dr. Dragado, que se siente muy bien, que está yà en actitud de trabajar y se halla muy satisfecho y agradecido de su curacion.

Comprobado esto, es dado de alta como definitivamente curado, el 18 de Febrero de 1922.

Es este un interesante caso de Síflis Cerebral eficazmente dominado por el método de WAG.NFR-JAUREGg, ásociado, como de costumbre, al tratamiento arsenical que solo, no habria dado los brillantes resultados obtenidos bajo la compleja acción de la inoculación malárica.

Este enfermo ha siclo observado recientemente: se halla perfectamente bien.

Restimen:

Núméro de inoculaciones: 3 (fallidas, $x$ ).

Sangre inoculada: $3 \mathrm{cc}$. (en total).

Número de accesos: 16.

Temperaturas: $38^{\circ}-41^{\circ}$ (en 13 accesos, más de $40^{\circ}$ ).

Resultado: Cunación completá. (1).

(1) No se empleó en este caso nucleinato, tuberculina ni ningún otro elemento piretogeno, fuera de la malaria. 
Observación $N^{\circ}$ 9.-I. A., residente en Lima, de 39 años de edad, blanco, católico, electuicista, ingresa por segunda vez al Asilo el 12 (te Julio de 1921.

Trasladado al servicio el día 21, se muestra tranquilo, coherente y lácido, manitestando que tiene la seguridad de salir pronto de acuel lugar en cuanto los médicos se convenzan de que no está loco, que sólo tiene mal la sangre, de lo que desea curarse, y de que ha sida llevalu alli por intrigas de su esposa. Tiene temblor en las manos, disartria acentua. da, esbozos megalomanos, inestabilidad en la marcha, disnrnesia.

Como antecedentes, nada comprobarlo por via de herencia. Es el tercero de cinco hermanos, uno de los cuales ha muerto del corazón, como el padre. Es casalo y tiene cuntro hijos cuyo grado de natalidad ignoramos. El ambiente familiar del sujeto es malo: malerata a su esposá, án cuando es amable con sus amigos. Vida disipata. Bebedor moderado. Chancro duro y adenitis hale aluince años. IIace tres, episodio psico-patológico con cambion de carracter, fugal de ideas, iacoherencia, estravagancial, celos. Hirce un aro tuvo un an taque a poplético, perdiendo el hablar y d luso de sus facultades mentales. Ocho dias más tande, nuevo ataque con los mismos carácteres, temblores en lás mános, disartia, incoordinación motríz, delirio de grandezas; estado que se agravó a consecuencia de ana disputa con su esposal.

Esto ocurria en Mayo de 1920, y en vista de sil estado fué traído al Asilo, en donde permaneció desde el 13 de Junio de 1920 , hasta el 5 de Julio del mismo año, en que fué dado de aita a solicitud de la familia, y contratiando la voluntad del médico tratante, notablemente aliviado. Dumante los 22 díasde perunanencia en el servicio acjuella primera vez fué so. meticlo sólo a lá acción de yoduros.

Como el estado de su enfermedad continuaba empeorando cada dia más, la familia volvió a int"rnarlo al A silu el 21 de Julio de 1921.

A poco de este segundo ingreso, se comienza a ágitar psicomotrizmente, con ideás de fugá y desorientación crono y endopsíquica. La reacción de WassermanN, en la sangre resulta medianamente positiva y el exámen del líquido céfaloraquíleo dá una $R$. W. fuertemente positiva; albúminas, 0.710 p. mil; linfocitosis, 12 p. mm. 3. Este confirma el diag. nóstico de parálisis general progresiva.

Como tratamiento sintomático, clinoterapia, bromuros, 
cloretona, isobromil, a más de que se le aplica una serie completa de neo-salvarsán y se le administra yoduros.

El 28 de Octubre (1921), se le inocula subcutánenmente $1 \mathrm{cc}$. de sangre malárica, a plasm. vivax. Desde el 6 de No. viembre experimenta malestar y la orina fuertemente cargada de pigmento, lo que hace presumir que tiene elevaciones térmicas en las noches. Estas se comprueban a partir del 8 , alcanzando $38^{\circ} 2$, con sudor copioso. En total tiene hasta cuatro accesos comprobados, de mediana in tensidad, desapa. reciendo espontáneamente.

Su estado mental, mejora un tanto, disminuyendo la agitación psíquica. Nueva serie de neo-salvarsán, alternadas con biyoduro de mercurio.

El 17 de Diciembre, nueva inoculacion de $1 \mathrm{cc}$. de sangre malárica, subcutáneamente; pero esto no produce ninguna reacción. Coleccionista y cleptómano, misántropo, con disartria muy acentuada.

E1 28 de Enero (1922), tercera inoculacion de sangre málárica, 2 cc. Gatismo urinario frecuente. Ninguna reacción febril en los cuarenta días posteriores a la inoculación. Ei temblor general se acentúa, especialmente en las manos y en la lenguá.

El 28 de Marzo, cuáta inoculación de sangre malarica, 2 cc. Ningún resultado. Ládisartria se torna anártrica. La marcha es lenta. No duerme. Está delirante y muy agitado. Se le aplican algunas inyecciones de tuberculina, con solo muy ligeras reacciones febriles.

El 19 de Abril se le inocula por vía endovenosa, 1 cc. de sangre málárica. Como no se obtiene ningún resultado, diez días después, nueva inoculación con $2 \mathrm{cc}$, vía endovenosa. En 9 de Julio comienzan a presentarse reacciones febriles de mediana intensidad, que fluctrian entre $37^{\circ} 0$ y $39^{\circ} \mathrm{C}$.

Cuando ha soportado cuatro o cinco accesos y a conse. cuencia de estos comienza a declinar la gran agitación psicomotriz, disminuyendo el temblor general del cuerpo y la disartria y mostrándose más tranquilo y orientado, a instancias de la familia, a pesar de la opinion en contra del médico del servicio, se le da de alta, definitivamente, el 15 de Junio de 1922; habiéndosele cortado antes los accesos paladicos con inyecciones de quinina. La mejutía a penas comenzaba a esbozarse. 
Meses despues, murio en su casa. Se ignora la causa directa de la muerte.

Resumen: Número de inoculaciones: 6 (fallidas, 4).

Sangre inoculada: $9 \mathrm{cc}$.

Numero de accesos: 9.

Temperaturas: $37^{\circ} 5-39^{\circ}$.

Resultado: Casi sin modificación.

Observacion $N^{\circ}$ 10.-A. J. U,, natural de Ica, residente en Lima, de 43 años, casado, ingeniero, raza blanca, católico, condición economica buena. En 1904 turo una crisis de "neurastenia" causada, segán el enfermo, por una intoxicación. En 1914 contrajo la infección. Los primeros síntomas de la enfermedad se hacen manifiestos en 1917, a los 38 años de edad. Se inicia con cámbios de carácter y una serie de ano. malias de la conducta y sintomas paralíticos. Tres años más tarde tiene un ictus a poplético, y en Julio de 1921 otro ataque que origina esta vez monoplejía izquierda, por lo que es internado en el Asilo el 27 ae Julio de 1921.

Está tranquilo y lácido. Exámen somático revela: a nisocoria, Argyll Robertson, Babinskresbozadoen el pié izquierdo, reflejo patelar aumentado. Conocidos sus antecedentes específicos con un tratamiento muy intenso, se practica el exámen del líquido céfalo-ráquídeo el que con fecha Dic. 10 , 1921, arroja el siguiente resultado: R. W., negativa; linfoci. tosis, 4 p. mm. c., albumina, 0.380. El examen de orina no ndica nada de particular, y el de sangre, practicados un pocoantes, arroja 4.340.000 hematíes con una leucocitosis considerable de 23.500 , debido a un proceso supurativo gangre. noso muy grave de la región ancra, por clećrbito brolongado.

Diagnóstico: Parálisis general progresiva.

Algunos antecedentes: Son cinco hermanos, uno de ellos neurbtico, hijos de mátrimonio consanguíneo; la madre vive -sana, el padre falleció a los 40 años de neumonia; el abuelo paterno, a los 80 , de arterioesclerosis, lá ábuela materna, a los 70, de carcinoma gástrico. Hogar tránquilo, nueve años de casado, cinco hijos, el menor de cuatro meses en la fecha del primer ingreso. Ambiente familiar felíz. Como anteceden. tes persongles: alumbramiento normal, lactancia materna; palabra, dentición y marcha, precóz; nada en la primera ni 
segunda infancia; pubertad normal; escolariedad, conducta y aprovechamiento exelentes; fórmula psicológica normal, inteligente, caracter fuerte y dado siempre al misticismo; dolores osteócopos, reumatoides. La enfermedad se iniciá len. tamente, con cambios de curácter, rarezas, coleccionismo, tics, violencias, delirio de persecucion; disartria y demás signos de demencia paralítica. Ictus apopletiformes. Monoplejía izquierda. Mejoría alconvalecer de la escara sacra (debida pro. bablementea la fiebre y reacciones biológicas provocadas por la supuración). Fórmula global: delirio místico.

Ingresá al servicio el 30 de Octubre. después de haber estado en observación en el Fabellón de Admisión.

Despues de una serie de neo-salvalrsan, el 2 de Diciembre (1921) se le inocula por primera vez, 1 cc. de sangre malári. ca vía subcutánea; inoculación que es repetida el día 17 del mismo mes por no haber producido reacción la primerá, presentándose la tiebre el 30 de aquel mes.

Los accesos tebriles siguen el ritmo terciano zon bastante regularidad, produciéndose hasta doce accesos, cuya temperatura oscila entre $38^{\circ}$ y $39^{\circ} 6$; son detenidos con una sola inyección de quinoformo, ( $1 \mathrm{gr}$.). Dulante este tiempo ha continuado con su delirio místico, presentando alucinaciones auditivas y visuales, todas de car ńcter divino. Tiene además delirio de persecución y delirio de grandeza muy acentuado. y está desorientado crono y alopsíquicamente. Así permanece hasta Abril del año siguiente (1922), mes en el cual se le practican a intervalos regulares varias inyecciones de "tuberculina" hasta de 15 miligla mos, sin obtenerse "ninguna reacciọn febril". Aclemás, se le ha a plicádo-una serie de biyoduro de mercurio.

El 29 de Abril se le inocula con $2 \mathrm{cc}$. de sangie malárica subucutáneamente, inoculación que por no producir resultado. es repetida el 13 de Mayo.

Como si está nuevá inoculación sirviera de reactivador de la primera, trascurridos apenas dos dias se presentá la primera reacción que se eleva a $40^{\circ}$, produciéniose hạsta ocho accesos, que se presentan sin interrupción en los ocho. diąs que siguen, con la particulatidad de ser, alternadamente, uno de intensidad fuerte y otro mediana, entre $37^{\circ} 5$ y $39^{\circ}$, los que, por la ligera debilidad que manitiesta el enferpo, sop detenidos con una iuyección de quinina.

Continga en su estado delirante, priesentando ademásanisocoria y rigịéz pupilar. Por esto se comienza una sẹtic 
de ocho inyecciones de "nucleinato de sodio" a dosis progresivamente crecientes aumentadas de cincuenta en cincuenta centigramos, cada tres días, las que producen "escasa" o "ninguna reaccion febril". Ninguna modificación en lá esfera psíquica, continuando su delirio de grandezas, mostrándose el paciente bastante irritable. Terminada el 10 de Julio la serie de inyecciones de nucleinato. después de veinte dias de descanso, el 30 , se comienza una serie de seis inyecciones de bismuto (Trep6l, de $0.10 \mathrm{gr}$. por cc.). Terminadala seriese nota una marcada mejoria de su estado mental, determinada äesde luego, no solamente por lá acción de este Gltimo mediamento, sino por lá acción conjuntá de los diversos elementos termogenéticos puestos en práctica. Han desaparecido los leltrios de persecución, disminuída la irrita. bilidad y el afán coleccionistá y cleptomano, mostrando además, voluntad para el trabajo.

En estas condiciones abandona el Asilo a sulicitud de la familia.

Reingresa el 11 de Marzo de 1923. Dos meses despues de estaren observacion, es trasladado al servicio, hábiendo presentado durante este tienupo marcadas tendencias a la fuga, alucinaciones auditivas, delirio míctico y persecutorio, megalomanía, coleccionismo, cleptomanía, glafomanía, hipomimia, par"aprosexial, dismnesia.

El 24 de Junio se comienza una serie de tifo-vacuna Besredka, traída, por el Jefe del servicio, del Instituto de Seroterapia de Viena, inyectándosele un décimo de centímetro cábico, vía endovenosa, cuyá técuica usual de administración es $0.1 \mathrm{cc}$. vía endovenosa bisemanalmente, aumentando la do. sis cada vez en medios o en un décimo de cc., según la intensidad de la reacción. Estás inyecciones son, en este enfermo, intercaladas con otras de biyoduro de mercurio. Las tres primeras dosis de vacuna solo producen escasa reacción febril, no asíla cuarta que es acompañada de $0.15 \mathrm{gr}$ de nucleina to de sodio, dos horas después de lo cual la temperatura se eleva a $39^{\circ}$, volviendo a la normal diez horas mas tarde. La reacción febril es precedida, como en los accesos maláricos de escalofríos intensos, seguidos de rubicundez y Gebre, después de la cual hay intensa palidéz y sudor copioso.

Consciente el enfermo de que estas diversas faces sun originadas por la inyección se irrita con el médico y enfermeros 
de quienes cree que le quieren matar, expresándose irónicamentede ellog - a veces en composiciones poéticas-diciéndoles que sus intentos son ińtiles "pues él está resguardado por el manto de la Vírgen Santísima...." Continfia con in. sistencia las alucinaciones visuales, teniendo constantes visiones celestiales. Una nueva inyección de nucleina to de sodio de $0.60 \mathrm{gr}$. determina en El reacción febril de $38^{\circ}$. Esto ocurre el 20 de Julio. El 24 del mismo mes una nueva inyección de 1 gr. determina una reaccion de $39^{\circ} 6$. En el mes de Agosto de aquel año (1923), recibe dos inyecciones de nucleinato, y cuatro en el mes de Setiembre, espacialas, con reacciones febriles que han oscilado entre $37^{\circ} 8 \mathrm{y} 38^{\circ} 8$, y otras tres en el mes de Octubre con analoga reacción febril, las que determinan intensa palidéz y marcado decámiento en el enfermo. Su esta. do mental continua sin modifiación manufiesta, megulómono, místico, favulador; tiene arersión al aseo y colecciona colillas de cigarro, palitos de fosforo, guarda las cenizas, etc.

A fines de Diciembre y en el curso de Enero del año 1924, se le aplica una serie de tifo-vacuna BESREDKa bisemanalmente en dosis progresivas que van de $0.1 \mathrm{cc}$. hasta llegar a $3 \mathrm{cc}$ y a fin a $3.5 \mathrm{cc}$. en las altimas inyecciones. Son en total quince inyecciones, algunas asociadas n inyecciones de dosis moderadas de nucleinato de sollio. Las cinco primeras casi nodeterminan reacción febrị, más 110 a sí las diez al timas que han determinado reacciones febriles que oscilan ${ }^{r} e n t r e ~ 37^{\circ} 5$ y $38^{\circ} 8$, en particulár cuando van asociadas al nucleinato de sodio.

Es interesante anotar que en el curso de esta serie, el enfermo, máslucido y consciente, ha podido darse cuenta de los diversos fenbmenos que en él iban determinando las in jecciones; manifestando en las que no determinaban reaccion intensa. "que no sentía fiebre pero sl un fuerte dolor de cabeza y gran depresion, seguida de una marcada sensación de bienestár y lucidez mental".

En ung ocasionen que la temperatura casi llegó a los $40^{\circ}$, referia al enfermo que ninguna inyección le habím producido tantos estragos y al mismo tiempo mayores beneficios ulte. rioresque aquella, y terminaba relatando que al principio sintió fiebre, sudando luego copiosamente, con cefalaligía, embrutecimiento, dolores musculares y gran relajácion muscular; todo lo cual desapareció al siguiente día, con voluntad para el trabajo, "y con el cerebro tan claro como en sus me. jores tiempos", todo lo cual arelata conlegría y optimismo. 
Sin embargo, contináa en su delirio aunque muy atenuado. Muy acentuado el coleccionismo.

El 11 de Abril (1924), es inoculado con 2 cc. de sangre malárica citratada, solución el $2 \%$ proveniente de un paralítico general que había sido a su vez inoculado de uná enferma paledica.

Ocho días despues presenta el primer acceso febril, de $38^{\circ}$ 2 y $39^{\circ} 5$. Por desgracia, sintomas manifiestos de insuficiencia hepática, obligan a suspender el tratamiento ingectando 1 gr. de quinina. Se le trata convenientemente y a poco esta complicacion eventual desapátece.

El 29 de Junio se le inyecta nuevamente, esta vez por vía endovenosa, $2 \mathrm{cc}$ de sangre malárica. Catorce días más tarde tiene un áceso febril de $39^{\circ} 5$, y dos días después, otro de $40^{2}$, los que desaparecen sin que se logre investigar la causa. Está inoculación se repite el 31 de Octubre, en lá misma formá que la anterior. Después de una incubación de 25 días (tiempo excesivo para una inoculación endovenosa), el 24 de Noviembre presenta el primer acceso febril, alcanzando $39^{\circ} 7$. Presenta así hasta cuntro accesos intensos que oscilan entre $39^{\circ} 5$ y $40^{\circ}$; a pesar de que es probable que haya tenido mas, pues a posteriorise quej6 de que durante las noches se ha sentido atiebrado. Esto haría pensar que aquel largo periodo de incubación ha sido tan solo a parente.

Singran modificación cu su estado mental trascurren los seis primeros meses del presente ano (1925). Para completar el tratamiento se le comienza a administrar una serie de Bismuto-yatrén (Beringwerke) tratámieuto que concluye, después de 45 días, el 15 de Junio, áplicado simultáneamente por vía endovenosa e intramuscular.

En resúmen, ha tenido hasta la fecha, 56 accesos rebriles comprobados, 29 de los cuales han sido producidos por la malaria y los 27 restarites por los otros medicamentos empleados; con temperaturas que han oscilado. casi en su totajidad, entre $38^{\circ}$ y $40^{\circ}$. El tratamiento malárico no ha podido intensificarse todavía más, a causa de la manifiesta into. lerancia del enfermo, en especial debido a complicaciones bépato-renales, que antes de su P. G. se manifestaron durante el tratumiento de su sífilis.

Actualmente, reconoce el error de sus sistemas delirantes del pasado. Su misticismo y sensibilidad narcicista s6lo se manifiestán al presente cuando el estímulo externo es excesivo. Siempre es algo coleccionista. Por lo demás, la religio- 
sidad acentuadar, el orgullo de su persona y de su familia, lat tendencian adquirit y guardar, fueton rasgos característicos de su personalidad normat.

Los únicos sintomas paralíticos que persisten son solo: a nisocoria, rigidéz de lá pupila izquierda, menguádal, reacción de la destchá al estímulo iuminoso.

Suestado mental ha mejorado visiblemente en estos frltimos neses. Podlía salir si su esposa no temiera un intento de agresion, como el que el paciente realizó en su salida de 1922. Por esta razón, el enfermo continka en el servicio. Es. tá láciclo, bien orientado y apto patat el trabajo; hace cálculosde matemácicas superiores, escribe bien, recuerda muchas nociones de su profesión qua habia olvidado.

Un último exámen de líquido céfalo-raquíleo, practicado e) 21 de Setiembre del año en curso (1925), arroja el siguiente resultado, -muy favomble para el enfermo: $R$. W., negativa; altúninas, 0.400 pesr mil (Sicard. Cantaloube): globulinasis, negativa (Ross-Jones); linfocilos, 1.7 por mm. 3. (en vez de 4 p. mm. 3, que tenía anteriomente); todo lo cual estál en armonía con su mejoría física y mentâl.

Estecaso es de un gian signilicado para nuestro estudio, dada la antigüedad y gravedad de la enfermedad cuando se inició el trătamiento.

Resumen: Número de inoculaciones: 7 (fallidas, 2 ).

Sangre inoculada: 12 cc. (entotal).

Número de accesos: 56.

Producidus por la nualaris: $29\left(38^{\circ}-39^{\circ} 6\right)$.

,. por 3 iny. tuberculina: 0 .

" por 16, nucleinato: $3\left(37^{\circ} 8-38^{\circ} 8\right)$.

" por 4 ." tifo-vacuna: $4\left(37^{\circ} 4-39^{\circ}\right)$.

" por $15 .$, idi. id. \%. nucleinato: $15\left(37^{\circ} 5.39^{\circ} 8\right)$

Total de arcecses: $\overline{0} 6$.

Resultado: Remision "quasi" complet

Observación $N^{\circ}$ 11. $-\mathrm{S}$. E.. raza blanca, de 36 años de edad, ingresa al Asilo el 4 de $M$ arzo de 1922, trancuilo pero con ideas de grandeza, disartriá, marcha vacilante. El exá-

(1) Sin incluír los originados por las escaras sacras que present 6 a su ingreso y cuyo uú wero no fue posible precisar. 
thien de líquido céfalo-raquídeo da tina $R$. W. fuertemente poSitiva; albuminosis, 0.560 p. mil; linfocitos, 12 p. mm. 3. Dragabstico: Parálisis general progresiva. Trasladado al servicio, se muestra desorietado, incoherente, temblor fibrilar en la lengua; disartria pronunciada: megalomanía.

Inoculaciónde 2 ec. de sangre malárica el 28 de Marzo de 1922. Ningún resultado. El 17 de Abril, 5 mgr. de tuberculi. na le ocasionan $38^{\circ} 5$. El 19, nueva inoculación de sangre malárica, 2 cc., presentándose en la noche $37^{\circ} 8$; el $21,40^{\circ}$, y el $23,39^{\circ} 5$, con escalotríos y sudor abundante. Aquí también la segunda inoculacion ha despertado la latencia de la inoculaciónanterior. Así se producen hasta 15 accesos con temperaturas de $38^{\circ}$ a $40^{\circ}$. Permarece quince dias ell apirexia, presentandu después otro hcceso el 3 de Junio, con $38^{\circ} 5$; teniendo en los días siguientes tres accesos mas de igual intengidad; después de los cuales se le aplica neo-salvarsán y quinina. Sin embargo, continfra delinante con alucinaciones visuales y auditivas. En los meses siguientes se le aplica una serie de neosalvarsán.

El 25 de Febrero de 1925, nueva inoculación con 2 cc. de sangre malarica, sin que se obtenga ningún resultado. Otra el 21 de Marzo, y una tercera (en ese $4 \pi \bar{n}()$, el 5 de Abril, presentándose el 8 el primer acceso con $39^{\circ} 8$, y el 10 otro con $40^{\circ} 5$; otro el 12 con $39^{\circ} 6$, el 14 con $40^{\circ}$ y el $x 6$ con $39^{\circ}$; des. pués apirexia. Cuartá inoculación el 24 y nuevá serie de cin. co accesos típicos entre el 2 y el 10 de $M a y$ o con temperaturas de $39^{\circ} 6$ a $40^{\circ} 4$. Doce dias de apirexia, y otros cinco accesos más entre el 22 de Mayo y el 2 de Junio, casi todos en. tre $39^{\circ}$ y $40^{\circ}$. En total, 15 accesos en alquel año (1923), originadus por el paludismo.

En noviembre y diciembre se obtienen, bajo la acción de dosis crecientes de nucleinatu de sodio, seis reacciones febrides que varían en intensidal entre $38^{\circ}$ y $39^{\circ}, 6$, El 25 de Di. ciembie se hace otra inuculación $\left(1^{a} 5^{a}\right)$ con $2 \mathrm{cc}$. de sangre malárica.subcutáneanente, sin resultado, y otra: el 9 de Enero de $1924,3 \mathrm{cc}$ vía enlovenosa, obteniéndose el 16 un primeracceso degran intensidad con $41^{\circ} \mathrm{C}$., otro el 21 con $40^{\circ} 5$ y otro el $23 \operatorname{con} 39^{\circ}$; después, apirexia.

Bajolat acciónde estas diversas reacciones ba tenido marcadas nuejorias en su estado mental y físico; pero a su delirio ruidoso y euforico de antes, ha sucedido ahora un estado de epatía e indiferenciá por cuanto le rodea. Continúa ligeramente disártrico. 
En el curso del año 1924, se le practican cinco inoculaciones con sangre malárica entre 2 y 4 cc., citratada, vía endovenosa, las cuatro primeras de las cuales, sin ningún resulta. do reaccional. La ́1tima, practicada el 31 de Octubre, produce, después de 23 dias de incubación, una serie de 10 acce. sos típicos, intensos, con temperatuas que casi siempre han llegado y pasado los $40^{\circ} \mathrm{C}$., entr el 22 de Noviembre y el 14 de Diciembre.

Elestado mentales relativamen te satisfactorio al comenzar el año 1925; pero la disartria permanece casi sin modificación.

Un proceso gastro-entérico desuutre y debilita notablemente al enfernio, quien debido a esto no puede alimentarse en debida forma. El sueño es también interrumpido, debido a la misuna causa.

Tantolossíntomas paralíticos como el estado mental del enfermo mejoraron bastante bajo la acción del tratamiento, desapareciendo el estado de perenne agitacion, para tornar. se un enfermo docil y tranquilo.

Desgraciadamente, el debilitamiento originado por sus trastornos digestivos, cuya exactá nat tualeza no fuć posible precisar, acaban con la agotada resistencia del enfermo.

Resúmen: NǴmero de inomlaciones: 13 (fallidas, 8).

Sangre inoculada: $30 \mathrm{cc}$. (en total).

Numero de accesos: 47 . (1).

Temperaturas: $38^{\circ}-40^{\circ} 5$.

Resultado: Mejoría.-Muerte (por afección gastro-entérica).

Observación $N^{9} 12 .-C$. M., natural de Lima, de 36 años de edad, casado, raza blanca, contador, ingresa al Asilo por primera vez, el 23 de Marzo de 1922. Está bastante lúcido, bien orientado; pero con marcha vacilante, disartria acentuada, desigualdad pupilar. No hay delirio. Se dá cuenta de suenfermedad. El exámen de líquido céfalo-raquídeo, da una R. W. fuertemente positiva, con 8 linfocitos por mm. $3, y$ 0.470 de albumina p. mil.

Se hace el diagnóstico de paralisis general progresiva. Trasladado al servicio, el 28 de aquel mes (Marzo), es inocu-

(1) Más 6 accesos debidos al nucleinato y 1 a la tuberculina, 10 que hace un total de 53 reacciones febriles. 
lado ese mismo día con 2 cc. de sangre malarica, procedente de un guardián que sufre accesos paladicos. Visitado al siguientedía porvarios miembros de su familia, se conduce con ellos correctamente, reconociéndolos a todos. Nada anormal en las pupilas. Huy algo de amnesia anterógrada.

Como la primera inoculación no dá resultado, el 17 del mes siguiente (Abril), se le inyecta $2.5 \mathrm{cc}$. (5 miligramos) de tuberculina. La disartria es más acentuada, camina con difeultad, duerme poco. Se queja de sentir algo extraño en su organismo; distingue borrosamente los objetos y se dá cuenta de la dificultad que tiene para pronunciar las palabras; está muy nervioso. Lá dismnesia se acentua. Esta melancólico. Despierta en las noches diciendo que se muere. Dieciseis dias después de la Giltima inoculación presenta una elevación térmica de $38^{\circ} 8$, sin escalofríos ni fiebre, comprobándose la presencia de hematozoario en la sangre. Los accesos se repiten tres veces, pero de intensidad muy moderada; son cortados por la quinina, pues la tamilia piensa sacar al enfermo; pero desistiendo aquella de su intent(), el 13 de Mayo se le inoculan otros $2 \mathrm{cc}$. de sangre malálica. Desgraciadamente, antes de que termine el período de inoculación y se dejen sentir los benéficos efectos de los accesos palúdicos sobre el estado físico y mental del enfermo, sale este del Asilo, a solicitud de la familia, el 24 de Junio de aquel año (1922), muy áliviado, tanto en la esfela física como en la mental.

Reingresa al Asilo, por segunda vez, el 29 de Febrero de 1924. Presenta está vez, disgrafia, disartria, alucinaciones visuales y auditivas, amuesía, sentimientos abolidos, abulia, disprosexio, hipomimia, estado confucional; presentando esta vez todas las características de una paralisis general pro. gresiva, las que s6lo estaban ligeramente en su primer in. greso.

El 9 de Marzo de 1924, ingresa nuevamente al servicio, del que saliera muy aliviado en Junio de 1922.

Está agitado y con los síntomas físicos y mentales que acabamos de indicar. Hay disartria ma rcada, temblor en las manos y a taxia. Hay delirio de grandezas, cleptomanía, hipoafectividad, gatismo urinario y tecal. Cree estar en perfecto estado de salud, por lo que pretende constantemente salir del pabellon.

El 14 de Abril se le inocula con 2 cc. de sangre malárica 
citiatada: via éndovenosa. Tiene delfrio hipocondriaco, ćré. yéndose sîi vientre, sin cuerpo. Está coństantemente exitádb. Hay paralisis del brazo derecho, con impótencía funcional. Siente que el pabellón dá vueltas, derrúmbándose, pór lo que trata de escapar.

En vistu de que la inoculación no ha dado resultado alguno, se le inocula nuevamente cón 4 çc. de sangre malárica citratáda, el 5 de Mayo. Está inoculación támpoco dá reácción, áńn cuando el enfermose muestra mucho más tranquilo y coherente, al punto de reconocer y departir correctamente con una sobrina que va a visitarlo por encargo de la familia.

Tal es su estado án en el mes de Junio, siendo el raggo más saltante el negativismo, pues rechaza en parte a alimentarse y se niega a levantarse de la cama en la que permainece más de un mes, no obstante los esfuerzos e insinuaciones del personal del servicio, negándose támbién a ingerir medicinas. Se le administra en el períndo de depresión un trata. miento opoterápico de extracto tiroideo, en inyecciones, alternando con otras de nucleinato de sodio.

El día 29 de Junio se le inocula por vía endovenosa con 2 cc. de sangré malárica, suspendiéndose por este motivo el tratamiento tiroideo y la serie de nucleinato de sodio; la que dicho sea de pasoo, no lograba producir reacción tebril. Continúa eri el mismo estádo, negándose a levantarse y aún a alimentarse, lo que, unido al estado de gran agitación psicomotriz, lo va debilitando progresivamente.

Sin que llegue a producir fiebre alguna la serie de inoculaciones, fillece el 7 de Julio de 1924.

Es indudable que este enfermo, que tan gran mejoria obturo en su ingreso, habría curado a no ser por la tátal insis. tencia de la tamilia en sacarlo, cuando estaba en pleno tra. tamiento y a tiempo á́n pála alcanzar una vuelta completa a la normalidad.

Restimen: NGmero de inoculaciones: 8 (fallidas, 3 ).

Sangre inoculada: $12 \mathrm{cc}$. (en total).

Numero de accesos: 4 .

Temperaturas: $37^{\circ} 5-38^{\circ} 8$.

Resultado: Mejoría, en la primera crisis.

Resisteuciát ante la infeccion malárica, en la segunda. Muerte. 